"Los desaparecidos empiezan a hablar": una aproximación histórica a la producción testimonial de los sobrevivientes de la dictadura argentina desde el exilio (1976-1983)

Rodrigo González Tizón

páginas / año 13 - n 31 Enero - Abril / ISSN 1851-992X/ 2021

http://revistapaginas.unr.edu.ar/index.php/RevPaginas

DOI: http://dx.doi.org/10.35305/rp.v12i30.473

\title{
"Los desaparecidos empiezan a hablar": una aproximación histórica a la producción testimonial de los sobrevivientes de la dictadura argentina desde el exilio (1976-1983)
}

\section{'Disappeared begin to speak': a historical approach to Argentine dictatorship survivors' testimonies in exile (1976-1983)}

\author{
Rodrigo González Tizón \\ Instituto de Altos Estudios Sociales; \\ Universidad Nacional de San Martín; \\ Consejo Nacional de Investigaciones Científicas y Técnicas (Agentina) \\ rgtizon@gmail.com
}

\begin{abstract}
Resumen
Este artículo plantea un abordaje histórico de la producción testimonial que realizaron desde el exilio los sobrevivientes de los centros clandestinos de detención (CCD) de la última dictadura argentina. En este marco, se reconstruyen los principales ámbitos de circulación pública de sus relatos sobre el cautiverio y se ofrece un análisis de su evolución a lo largo del período 1976-1983. El trabajo se propone no sólo recuperar su aporte específico a la lucha contra el régimen militar, sino también tensionar la construcción de sentidos que postula el silenciamiento público de los sobrevivientes a causa de las acusaciones de "traición". Finalmente, se exploran las modulaciones específicas que asumieron, en la producción testimonial de los sobrevivientes, una serie de fenómenos que atravesaron al movimiento antidictatorial exilar en su conjunto: la elaboración de saberes tempranos sobre el dispositivo represivo clandestino para su difusión en el extranjero, la relación entre las lógicas políticas revolucionaria y humanitaria en el ejercicio de la denuncia, la naturaleza transnacional de las redes de activismo antidictatorial y la construcción de diferentes categorías de víctimas de la violencia represiva.
\end{abstract}

Palabras Clave

Sobrevivientes de centros clandestinos; testimonio; exilio; denuncia; dictadura.

Esta obra está sujeta a la Licencia Reconocimiento-NoComercial-CompartirIgual 4.0 Internacional de Creative Commons. http://creativecommons.org/licenses/by-nc-sa/4.0/ 


\title{
Rodrigo González Tizón
}

\begin{abstract}
This article proposes a historical approach to the testimonies produced in exile by the Survivors of clandestine concentration camps during Argentina's last dictatorship. In this context, the text analyses their main spheres of public circulation and its historical evolution throughout 1976-1983. The article aims not only to recover their contribution to the struggle against military regimen but also to challenge the common sense of survivors' public silencing due to accusations of 'betrayal'. Finally, this whole assembly allows to explore how a series of phenomena characteristic of anti-dictatorship exile activism materialize in survivors' testimonies: the early production of knowledge about the clandestine repression, the relationship between revolutionary and human rights political cultures, the transnational nature of the exile activism networks and the construction of repression categories of victims.
\end{abstract}

\section{Keywords}

Survivors; testimonies; exile; denounce; dictatorship.

\section{Introducción}

En marzo de 1977, la Comisión Argentina de Derechos Humanos (CADHU) publicó en Madrid el informe Argentina: Proceso al Genocidio ${ }^{1}$. El documento denunciaba las acciones represivas que se desarrollaban en el país desde 1975 y, especialmente, a partir de marzo de 1976. Las enmarcaba en una "campaña oficial de persecución política e ideológica" que había asumido la forma de un "Terrorismo de Estado"2. En el mismo momento en que se publicaba este escrito, Amnistía Internacional (AI) presentaba en Londres el informe con los resultados de la misión enviada a la Argentina en noviembre de $1976^{3}$. Allí se afirmaba que el accionar de la Junta Militar "a fin de restaurar la seguridad (...) ha creado una atmósfera de terror"4. A pesar de sus diagnósticos divergentes sobre la represión, ambos documentos acordaban en que en la Argentina de la época se violaban los derechos humanos. Su circulación por distintos países de América y Europa contribuyó al conocimiento internacional de los crímenes dictatoriales.

La principal evidencia sobre la que reposaban las acusaciones de Argentina: Proceso al Genocidio y del informe de AI eran los testimonios de un conjunto de personas que habían salido con vida de los denominados centros clandestinos de detención (CCD). Frente a los intentos de la Junta Militar de negar las violaciones a los derechos humanos en la Argentina, las voces de los sobrevivientes describieron de manera precisa y en detalle los secuestros, las torturas y las condiciones de cautiverio en los espacios de reclusión ilegal dictatoriales. Sus relatos, al exponer el horror en

\footnotetext{
${ }^{1}$ CADHU, Argentina: Proceso al Genocidio, Madrid: Elías Querejeta Ediciones, marzo de 1977.

${ }^{2}$ Ibidem, p. 9.

${ }^{3}$ Amnistía Internacional, Informe de una misión de Amnistía Internacional a la Argentina, 6-15 de noviembre de 1976, Barcelona: Amnesty International Publications, 1977.

${ }^{4}$ Ibidem, p. 67.
} 


\section{“Los desaparecidos empiezan a hablar": una aproximación histórica a la producción testimonial de los sobrevivientes de la dictadura argentina desde el exilio (1976-1983)}

primera persona, respaldaron las denuncias de organismos de derechos humanos y familiares de los desaparecidos (Franco, 2008), contribuyendo a la condena internacional del régimen.

Los informes de la CADHU y de AI iluminan una faceta poco explorada del activismo antidictatorial en el exilio: la participación de los sobrevivientes de los CCD en las redes de denuncia transnacionales a través de la elaboración de relatos sobre el cautiverio. Esta producción testimonial más allá de las fronteras argentinas se desarrolló con intensidad variable a lo largo de toda la dictadura. Para muchos sobrevivientes, el exilio se constituyó como "un tiempo-espacio de posibilidad para la elaboración y la presentación pública de sus denuncias" (Tello, 2015: 97). Fruto de la intensa represión estatal y de la amplitud y heterogeneidad que revistió la diáspora argentina, esa producción se estructuró en torno a diversos "circuitos testimoniales" con base en las distintas entidades que acogieron y dieron a conocer la palabra de los sobrevivientes (González Tizón, 2016). Estos ámbitos de elaboración, recepción y difusión de testimonios asumieron rasgos específicos, pero también evidenciaron múltiples intersecciones.

El protagonismo que asumieron los sobrevivientes como testigos de los crímenes dictatoriales durante la transición democrática dejó en un segundo plano su producción testimonial previa. Como consecuencia, durante mucho tiempo su participación en las iniciativas de denuncia del exilio no constituyó un objeto de interés en sí mismo. Sólo fue abordada de manera secundaria en el marco de trabajos académicos que estudiaron las acciones desplegadas por organizaciones e individuos fuera de la Argentina (Crenzel, 2008; Franco, 2008; Jensen, 2010; Yankelevich, 2010), de investigaciones periodísticas sobre organismos internacionales (Gutman, 2015) o de escritos de referentes de los derechos humanos (Fernández Meijide, 2009; Rocha, 2018). Recientemente, algunos investigadores pusieron el foco en lo ocurrido con los sobrevivientes durante la dictadura a través de estudios de caso. Estos trabajos sacaron a la luz su agencia política más allá de la figura del testigo (González Tizón, 2018; Ayala, 2019), su inserción en las redes de denuncia humanitaria internacionales (Rama, 2019) y su aporte al conocimiento temprano de la represión (Tello, 2015; González Tizón, 2016; Tolentino, en prensa). Claves para reconstruir trayectorias de actores o coyunturas particulares, estas investigaciones no se aproximaron a los sobrevivientes y sus relatos desde una óptica general.

Este artículo plantea un abordaje de conjunto de la producción testimonial de los sobrevivientes desde el exilio que, al tiempo que recupere su aporte específico a la lucha contra el régimen militar, ofrezca también un análisis de su evolución histórica. En esta línea, se propone la existencia de tres etapas en esa producción de relatos, cuyo trasfondo común fue la denuncia del cautiverio clandestino. Durante la primera, extendida entre el golpe de Estado y marzo de 1977, los testimonios de los sobrevivientes, todavía esporádicos, aportaron las coordenadas básicas para dar a conocer en el extranjero la especificidad de la represión en la Argentina. La segunda, 


\section{Rodrigo González Tizón}

transcurrida entre el primer aniversario de la dictadura y la visita de la Comisión Interamericana de Derechos Humanos (CIDH), fue el momento de conformación de los principales circuitos testimoniales en el exilio, cuya impronta política abarcó todo el ancho del espectro ideológico. A partir de 1979, y hasta el retorno de la democracia, el pico de difusión pública de la palabra de los sobrevivientes coexistió con la consolidación de nuevos formatos para la denuncia y con las tensiones generadas en torno al contenido de los testimonios.

El análisis propuesto, además, tensiona una construcción de sentidos nodal en la conformación de un campo estudios en torno a los sobrevivientes, retomada en mayor o menor medida por diversas investigaciones: su silenciamiento público a causa de las acusaciones de "traición" que pesaron sobre sus espaldas luego de su salida de los CCD (Longoni, 2007). Si bien no contradice la existencia de estos señalamientos, la extensa producción testimonial de los sobrevivientes durante el período dictatorial da cuenta también de un "espacio de escucha" abierto a su palabra en el marco del activismo antidictatorial exilar 5 . Un recorrido histórico por esa producción de relatos, en consecuencia, permite abordar el silenciamiento público de los sobrevivientes no ya como un fenómeno generalizado sino como uno que arraigó en determinados actores y coyunturas específicos.

Finalmente, una aproximación como la que se plantea en este artículo ilumina las modulaciones específicas que asumieron, en la producción testimonial de los sobrevivientes, una serie de fenómenos que atravesaron al movimiento antidictatorial exilar en su conjunto. Entre otros, permite explorar la elaboración de saberes tempranos sobre el dispositivo represivo clandestino con miras a su visibilización en el extranjero, la relación entre las lógicas políticas revolucionaria y humanitaria en el ejercicio de la denuncia, la naturaleza transnacional de las redes de activismo antidictatorial y la construcción de diferentes categorías de víctimas de la violencia represiva.

El trabajo con los relatos producidos por los sobrevivientes en el exilio plantea algunas dificultades debido fundamentalmente a la clandestinidad y urgencia que rodeó su elaboración y, también, a su gran dispersión geográfica. Dados estos obstáculos, la reconstrucción de los contextos de producción y circulación de la palabra de los sobrevivientes partió del entrecruzamiento de fuentes diversas, entre las que se incluyen testimonios editados, publicaciones de organismos internacionales y del exilio, artículos de prensa y entrevistas con protagonistas del fenómeno analizado.

\footnotetext{
${ }^{5}$ Diversos autores y autoras insistieron en que el testimonio de la experiencia concentracionaria es producto no sólo de la voluntad de denunciar de los sobrevivientes sino, también, de contextos políticos y modos de solicitación de la palabra específicos que favorecen la emergencia de esos relatos (Calveiro, 2006; Pollak, 2006; Tello, 2015).
} 


\section{“Los desaparecidos empiezan a hablar": una aproximación histórica a la producción testimonial de los sobrevivientes de la dictadura argentina desde el exilio (1976-1983)}

\section{Noticias tempranas del cautiverio: los primeros testimonios en el exilio y la construcción de saberes sobre la represión clandestina}

Durante el primer año de dictadura, la urgencia por salvar a los desaparecidos constituyó el motor de la denuncia en el plano internacional. Para eso, se percibía como condición necesaria lograr la condena de la Junta Militar en el extranjero. Esta tarea no era sencilla. La espiral de violencia del tercer gobierno peronista había contribuido a que el golpe de Estado de 1976 fuera percibido por muchos actores, dentro y fuera del país, como una iniciativa tendiente a "ordenar" el caos político interno (Franco, 2012). Una impresión que se veía apuntalada por el aura de "moderación" instalada en torno a la figura del presidente de facto Jorge Rafael Videla, en contraposición a un supuesto "sector pinochetista" de las Fuerzas Armadas (Jensen, 2010). El logro de la solidaridad se dificultaba, además, en sociedades que, como las europeas occidentales, identificaban la práctica armada con el terrorismo (Franco, 2008). Finalmente, la naturaleza clandestina del grueso de la actividad represiva dificultaba probar la responsabilidad estatal en los crímenes, cuya autoría era sistemáticamente negada por el gobierno de facto. Por consiguiente, la prioridad de los denunciantes era persuadir a sus interlocutores extranjeros de la gravedad de la situación argentina y de la responsabilidad estatal en los secuestros, torturas y asesinatos.

Los testimonios de los sobrevivientes irrumpieron en el espacio público exilar en el marco de este activismo antidictatorial. Inicialmente, su circulación fue cuantitativamente reducida. Si bien resulta imposible dar una cifra definitiva por las dificultades que supone esa reconstrucción, un rastreo por numerosas y heterogéneas fuentes del exilio permitió contabilizar alrededor de una decena de relatos, la mayoría de los cuales fueron publicados en diciembre de 1976. En términos espaciales, su circulación temprana abarcó al menos cuatro países: Inglaterra, México, Estados Unidos y Francia. A ellos habría que sumarles la ciudad de Ginebra, donde tenían su sede la Organización de las Naciones Unidas (ONU) y otros organismos internacionales que tempranamente se convirtieron en puntos de recepción prioritarios de los relatos ${ }^{6}$.

Piezas fundamentales de la campaña de denuncia en el extranjero, las organizaciones internacionales de derechos humanos constituyeron un primer polo de difusión de la palabra de los sobrevivientes. Dentro de este conjunto, AI desempeñó un rol pionero. El 16 de agosto de 1976, el organismo publicó en Londres Testimonies on persons, torture and detention in Argentina, donde incluyó el relato anónimo de una mujer que había salido con vida de un espacio de cautiverio clandestino. El documento constituyó, hasta donde fue posible reconstruir, la

\footnotetext{
${ }^{6}$ A pesar de ser una referencia obligada para los denunciantes, la ONU planteó dificultades iniciales para quienes buscaban la condena de la dictadura. Esto se debía a los vínculos comerciales que unían a la Junta Militar y la Unión Soviética, cuyo voto era necesario para el tratamiento del caso argentino por parte del organismo internacional (Franco, 2008).
} 


\section{Rodrigo González Tizón}

incursión más temprana de la palabra de los sobrevivientes en el espacio público internacional ${ }^{7}$.

Dentro del terreno gubernamental, la Cámara de Representantes de Estados Unidos se mostró tempranamente receptiva a los testimonios del cautiverio clandestino. Esta actitud se enmarcaba en el giro más amplio de la política norteamericana que se inició durante la campaña presidencial del demócrata Jimmy Carter. A partir de entonces, y todavía más luego de su victoria en los comicios, los derechos humanos ganaron un espacio considerable en la agenda pública local. En el contexto de este nuevo clima político, la iniciativa de políticos como el senador demócrata Donald Fraser y el lobby de grupos comprometidos con la denuncia de los crímenes de la dictadura como el Olga Talamante Defense Committee (OTDC) permitieron llevar la discusión sobre la represión dictatorial a la Cámara de Representantes. Se realizaron audiencias (hearings) para determinar la situación de los derechos humanos en la Argentina y, en función de eso, definir la actitud del Ejecutivo norteamericano en relación a las ayudas militares a la dictadura y a un posible programa de refugiados. Allí testimonió, el 28 de septiembre de 1976, el sacerdote norteamericano James Weeks, secuestrado en la provincia de Córdoba junto a cinco seminaristas de su orden $^{8}$.

Una tercera correa de transmisión de los testimonios de los sobrevivientes fueron las organizaciones de exiliados. En esta etapa inicial, la difusión de los testimonios fue encarada por entidades surgidas en dos destinos donde el activismo antidictatorial ganó peso tempranamente: México (Yankelevich, 2010) y Francia (Franco, 2008). El 12 de noviembre de 1976, el Comité de Solidaridad del Pueblo Argentino (COSPA), organismo vinculado a la militancia montonera en el primero de esos países, difundió una denuncia sobre los crímenes de la Junta Militar que tenía como base los relatos de presos políticos y sobrevivientes de $\mathrm{CCD}^{9}$. En Francia, la difusión de los testimonios estuvo a cargo del Comité Argentin d'Information et Solidarité (CAIS), entidad declaradamente apartidaria pero donde confluían militantes del PRT-ERP, Montoneros y de otros grupos trostskistas (Franco, 2008). En diciembre de 1976, el organismo publicó dos documentos en los que se

\footnotetext{
${ }^{7}$ Amnesty International, Testimonies on persons, torture and detention in Argentina, Londres, Agosto de 1976 (citado en Gutman, 2015: 43-44). Hasta donde logró reconstruirse, el documento fue pionero en incluir explícitamente la palabra de los sobrevivientes en una denuncia pública de los crímenes dictatoriales. Previamente, esta había aparecido de manera indirecta o solapada en las presentaciones de los familiares y/o en los escritos elaborados por organismos, por ejemplo, para dar cuenta de información sobre el supuesto paradero de algunos desaparecidos o sobre lugares que se sospechaban funcionaban como CCD.

${ }^{8}$ Sala de Representantes de los Estados Unidos, Audiencias ante subcomité de Organizaciones Internacionales, Segunda Sesión, 28-29 de septiembre de 1976. Weeks había sido citado a declarar debido a la relevancia pública que había adquirido su caso en Estados Unidos, donde las iniciativas emanadas desde la sociedad civil impulsaron gestiones diplomáticas por su liberación. En esa misma sesión del subcomité de Organizaciones Internacionales declaró también el abogado Gustavo Roca, integrante de la CADHU, procedente de España. Junto a él había viajado otro miembro del organismo, Lucio Garzón Maceda, exiliado en París, cuya declaración estaba pautada para el día siguiente.

${ }^{9}$ La denuncia del COSPA tomaba como base, a su vez, un informe elaborado por la Liga Argentina por los Derechos del Hombre (LADH). "Las calles de Buenos Aires son objetivos militares", El Día, 12 de noviembre de 1976. Disponible en el Archivo Nacional de la Memoria.
} 


\section{“Los desaparecidos empiezan a hablar": una aproximación histórica a la producción testimonial de los sobrevivientes de la dictadura argentina desde el exilio (1976-1983)}

recuperaban las voces de sobrevivientes de distintos espacios de reclusión clandestina ${ }^{10}$.

La novedad que planteaba la desaparición forzada de personas se tradujo, en esta etapa temprana, en una falta de categorías específicas para dar cuenta de la sobrevida a los CCD. Ante este vacío, la prisión política, que constituía una práctica represiva conocida y sobre la que existía una experiencia de denuncia acumulada, aportó los soportes y marcos de referencia para hacer pública la experiencia del cautiverio clandestino. En el caso de AI, la acción del organismo, desde sus comienzos en la década de 1960, se había focalizado en las gestiones humanitarias para la defensa de los llamados "presos de conciencia"11. Como parte de este esfuerzo, había denunciado las condiciones de detención y las torturas en las prisiones políticas de diversos países del mundo. Por lo tanto, la difusión de testimonios de personas detenidas en distintos penales de la Argentina no desentonaba con la línea histórica de la entidad. Lo novedoso de Testimonies... era la inclusión de un relato referido a la experiencia del cautiverio clandestino.

Esta presentación conjunta e indiferenciada de los testimonios de presos políticos y sobrevivientes fue una constante a lo largo del primer año de dictadura. Lo mismo sucedió, por ejemplo, en los documentos publicados por el CAIS en Francia. El primero de ellos, Prisons Argentines, planteaba una situación análoga a la del escrito de AI: si bien, como indicaba su título, el foco estaba puesto en la situación de las personas detenidas en los penales legales, entre los testimonios de los presos políticos se colaban, sin solución de continuidad, los de los sobrevivientes de los $\mathrm{CCD}^{12}$. El otro documento, Repression et torture, constituía una recopilación de relatos. Esta apuesta por la palabra "desnuda" de la víctima, cuya potencia fue descubierta tempranamente por los argentinos exiliados en suelo francés (Franco, 2008), recurría una vez más a la exposición conjunta de los testimonios de ambas experiencias de reclusión ${ }^{13}$.

La dificultad para pensar la experiencia de la sobrevida a los CCD por fuera de los marcos de la prisión política se expresó también en los modos de denominación de los sobrevivientes. En la denuncia difundida por el COSPA a través de la prensa mexicana en noviembre de 1976, quienes habían salido con vida de los espacios de cautiverio clandestino eran nombrados indistintamente como "ex presos", "personas que fueron secuestradas y torturadas [y] testimonian la vigencia del terror" o "detenidos que luego fueron libertados"14. En el caso del CAIS, se utilizaba un término procedente del campo léxico revolucionario: se hablaba del "camarada"

\footnotetext{
10 CAIS, Prisons Argentines, París, diciembre de 1976.

11 Más abarcativa que la de "preso político", la noción incluía también a personas perseguidas por su religión, sexo, orientación sexual o pertenencia étnica (Gutman, 2015). Sin embargo, contenía una exclusión taxativa: no entraban en la categoría quienes estuvieran acusados de haber cometido un delito de sangre, lo que en la práctica dejaba fuera a los miembros de la guerrilla.

12 CAIS, op. cit., diciembre de 1976.

${ }^{13}$ CAIS, Repression et torture, París, 1976.

${ }^{14}$ El Día, op. cit., 12 de noviembre de 1976.
} 


\section{Rodrigo González Tizón}

que había logrado fugar del lugar de detención ${ }^{15}$. Tampoco los sobrevivientes ensayaban una identificación basada en la especificidad de la experiencia vivida: la mujer que había prestado su relato a AI se presentaba a sí misma como "la esposa de un exiliado político"16. Otros testimoniantes simplemente se daban a conocer a través de datos biográficos básicos como su nombre, nacionalidad, edad u ocupación ${ }^{17}$.

En la ruptura con esa indistinción inicial jugó un rol central la analogía que los denunciantes del exilio trazaron entre la represión dictatorial y la masacre nazi. "Se ha llegado al genocidio", afirmaba el COSPA al difundir el informe de la LADH ${ }^{18}$. Mencionaba, además, la existencia de numerosos "campos de concentración" a lo largo del territorio argentino. La misma noción se utilizaba en uno de los documentos del CAIS donde, además, se hacía una mención explícita al "exterminio" de las personas secuestradas: "centenas de entre ellas son retiradas de los campos de concentración para ser fusiladas"19. En un contexto de revisibilización del Holocausto y de fuerte presencia de la palabra de las víctimas en el espacio público occidental (Wieviorka, 1998; Alonso, 2013), la analogía con la matanza nazi tenía un sentido estratégico para los denunciantes: les permitía "traducir" los crímenes dictatoriales a términos comprensibles para sus interlocutores extranjeros (González Tizón, 2016; Jensen, 2019).

En cuanto a su extensión y estructura, los testimonios que inicialmente vieron la luz en el exilio eran por lo general narraciones breves y ceñidas a la descripción fáctica del hecho represivo. El detalle de las torturas y del sufrimiento experimentado ocupó un lugar central en esos relatos tempranos: "Cuando pensé que iban a empezar [la tortura con picana], me arrastraron de los pelos y me tiraron en un baño; pusieron mi cabeza en el agua hasta que empecé a ahogarme", señalaba la testimoniante ante $\mathrm{AI}^{20}$. A la descripción de las torturas y sufrimientos propios se sumaba, también, la de los otros cautivos: "golpearon y llevaron a la mujer de [X] y nosotros escuchamos sus gritos junto a los de [X]"21. Esta descripción de los tormentos cumplía con la doble función de reforzar la autoridad testimonial de los sobrevivientes y exponer la atrocidad de los crímenes.

A pesar de no tener un formato claramente identificable o marcas gráficas que organizaran el texto, los relatos contenían un primer esfuerzo de ordenamiento de la experiencia -de por sí caótica y desestructurante (Calveiro, 1998; Tello, 2015)del cautiverio clandestino. En esta etapa temprana de la producción testimonial de los sobrevivientes, el criterio predominante fue el cronológico: con algunas pocas

\footnotetext{
15 CAIS, op. cit., diciembre de 1976, p. 15.

${ }^{16}$ Amnesty International, op. cit., agosto de 1976 (citado en Gutman, 2015: 43-44).

17 Así, por ejemplo, comenzaba Weeks su alocución ante la Cámara de Representantes: “Mi nombre es James Weeks, soy un sacerdote norteamericano que trabajó en Argentina durante los últimos once años" (Sala de Representantes de los Estados Unidos, op. cit., p. 2.).

18 El Día, op. cit.,12 de noviembre de 1976.

${ }^{19}$ CAIS, op. cit., diciembre de 1976, p. 16.

${ }^{20}$ Amnistía Internacional, op. cit., agosto de 1976 (citado en Gutman, 2015: 43-44).

${ }^{21}$ CAIS, op. cit., diciembre de 1976, p. 14.
} 


\section{“Los desaparecidos empiezan a hablar": una aproximación histórica a la producción testimonial de los sobrevivientes de la dictadura argentina desde el exilio (1976-1983)}

excepciones, los sobrevivientes organizaron la narración de su vivencia en base a la secuencia "secuestro-arribo al lugar de detención-cautiverio-liberación/fuga".

La fisonomía y el largo de los relatos iban en consonancia con el perfil de los sobrevivientes que testimoniaron durante los primeros tiempos de la denuncia. En su mayoría, habían atravesado un período de cautiverio breve antes de ser liberados o de escapar aprovechando un descuido de sus captores. Su conocimiento del dispositivo represivo, por consiguiente, era más bien acotado. A eso se sumaba la urgencia por hacer públicos los crímenes de la dictadura con la esperanza de salvar así todas las vidas posibles, lo que acortaba los tiempos de producción. Finalmente, no pocos de los testimonios que circularon en el exilio durante esa primera etapa se habían elaborado en la Argentina en plena la clandestinidad, con la precariedad y los peligros que ello traía aparejado.

Alineados con el objetivo de lograr la condena internacional de la dictadura, los testimonios de los sobrevivientes aportaron numerosas evidencias de la responsabilidad de la Junta Militar en las desapariciones. Un primer indicio de ello emergía en las descripciones de los operativos de secuestro. En su alocución ante la Cámara de Representantes, por ejemplo, Weeks señalaba que de su captura habían participado personas que, a pesar de estar vestidas de civil, “afirmaban ser policías"22. De manera similar, la autora del testimonio anónimo de Testimonies... sostenía que en el operativo que terminó en su secuestro habían participado unos "veinte civiles armados, que dijeron pertenecer al Ejército"23.

Estos indicios de la responsabilidad estatal en la represión se veían reforzados por la descripción que se hacía de los lugares de cautiverio, identificados como dependencias policiales y militares. "Torturas y asesinatos en Campo de Mayo" era el título con el que el CAIS introducía el relato de Julio Visuara, militante montonero secuestrado en esa guarnición militar, de la que había logrado fugar ${ }^{24}$. El testimonio de AI, por su parte, corría el foco del Ejército a la Armada al mencionar a la ESMA como un espacio de reclusión clandestina ${ }^{25}$. Finalmente, el sacerdote irlandés Patrick Rice, exiliado en Londres, relató haber permanecido secuestrado en la "comisaría 36" del barrio porteño de Villa Soldati26. Testimonios como los mencionados dejaban expuesta la participación directa de las Fuerzas Armadas y de Seguridad en la represión clandestina.

Los relatos de esta primera etapa sacaron a la luz, además, los vasos comunicantes fluidos que existían entre los CCD y las prisiones legales. Estas conexiones quedaban en evidencia, por ejemplo, en el testimonio de María del Socorro Alonso, integrante de la comisión de solidaridad de presos del PRT ${ }^{27}$. Incluido en la selección de

\footnotetext{
22 Sala de Representantes, op. cit., p. 2.

${ }^{23}$ Amnistía Internacional, op. cit., agosto de 1976 (citado en Gutman, 2015: 43-44).

24 CAIS, op cit., diciembre de 1976, p. 13.

25 Amnistía Internacional, op. cit., agosto de 1976 (citado en Gutman, 2015: 43-44).

${ }^{26}$ CAIS, op. cit., 1976, p. 2.

27 Idem.
} 


\section{Rodrigo González Tizón}

testimonios del CASI, su relato recorría su cautiverio clandestino en una comisaría y, luego, en la Superintendencia de Seguridad Federal -también conocida como "Coordinación Federal"-, hasta su legalización y detención en el penal de Devoto. En el mismo sentido iba el testimonio de Rice, quien luego de estar secuestrado sin reconocimiento en la comisaría 36va había sido llevado a la "Estación Central de Policía", donde había sido legalizada su detención ${ }^{28}$. Pocos días después fue trasladado al penal de Devoto y, finalmente, a La Plata, hasta su expulsión del país. Estas trayectorias refutaban la idea de que existía una distinción tajante entre el entramado represivo legal y el clandestino, el primero a cargo del Estado y el otro más allá de su control, mostrando su naturaleza imbricada.

El año 1977 llegó en un contexto donde la actividad represiva se mantenía en niveles similares a los de 1976. Este sostenimiento de la intensidad de los secuestros y las desapariciones, combinado con las dificultades para manifestarse dentro del país, reforzó el rol del activismo exilar. Dentro de este marco, los testimonios del cautiverio clandestino aumentaron su presencia en el espacio público extranjero. Su difusión correría a cargo de diversas entidades que, a pesar de sus diferentes concepciones políticas, coincidieron en la conveniencia de visibilizar las voces de los sobrevivientes. El punto de partida para esta nueva etapa en su producción testimonial sería la publicación de los dos primeros informes exhaustivos sobre la represión en la Argentina, coincidente con el primer aniversario del golpe de Estado.

\section{Derechos humanos y/o revolución: la conformación de los circuitos testimoniales en el exilio}

El derrotero que llevó a la publicación de Argentina: Proceso al genocidio estuvo marcado por la ferocidad de la represión dictatorial y por las redes de solidaridad del exilio. La CADHU había surgido en la Argentina a partir de la confluencia de fuerzas políticas de distinto signo político como respuesta a los crecientes secuestros, atentados y asesinatos que tuvieron lugar durante final del gobierno peronista, aunque su fundación formal tuvo lugar luego del golpe de Estado de marzo de $1976^{29}$. El interés de crear un organismo para la denuncia de la represión nació entre un conjunto de abogados con experiencia en la defensa de presos políticos durante las dictaduras previas (Rot, 2015). Entre sus fundadores se encontraban los militantes del Partido Revolucionario de los Obreros Argentinos (PROA) Eduardo Luis Duhalde, Carlos González Gartland, Haroldo Logiurato Carlos María Duhalde, Ignacio Ikonicoff y Marcelo Duhalde, entre otros, a quienes se

\footnotetext{
${ }^{28}$ Idem.

${ }^{29}$ No es sencillo establecer una fecha específica para la fundación de la CADHU. Según Carlos González Gartland, el organismo se creó en abril de 1976, información confirmada por un documento posterior (CADHU, Programa: Buro de Información Europeo de la Comisión Argentina de Derechos Humanos, París, 21 de abril de 1978). No obstante, la Asamblea Constitutiva donde se aprobaron la Declaración de Principios y el Estatuto de la CADHU -formalizando así el funcionamiento de la nueva entidadtuvo lugar en julio de 1976.
} 


\section{“Los desaparecidos empiezan a hablar": una aproximación histórica a la producción testimonial de los sobrevivientes de la dictadura argentina desde el exilio (1976-1983)}

sumaron los abogados cordobeses Gustavo Roca y Lucio Garzón Maceda ${ }^{30}$. Este núcleo inicial se nutrió, además, con nombres procedentes del universo de las organizaciones armadas, tales como Rodolfo Mattarollo, Manuel Gaggero, Martín Federico, Lidia Massaferro o Pablo Ramos, entre otros ${ }^{31}$. Los acuerdos del grupo del PROA con Montoneros y el PRT-ERP (Franco, 2008; Carnovale, 2011) permitieron a la CADHU obtener de manera temprana y veloz información detallada sobre la represión clandestina en la Argentina que, luego, el organismo volcaba en sus documentos de denuncia ${ }^{32}$. A su vez, esta confluencia de trayectorias y líneas políticas marcó la impronta de las intervenciones públicas de la CADHU, en las que la confluencia entre la discursividad revolucionaria y el lenguaje de los derechos humanos alcanzó su máxima expresión (Copello, 2019).

Desde sus comienzos, la CADHU otorgó un lugar privilegiado a la denuncia en el plano extranjero. Su estrategia consistía en presentar la represión en la Argentina "en términos violatorios del marco jurídico internacional" (Jensen, 2014: 5) ${ }^{33}$. Esta orientación se profundizó debido a los duros golpes que recibió el organismo durante el primer año de dictadura. Como consecuencia del secuestro de la mayoría de sus integrantes en el país, la representación exterior de la CADHU transmutó de facto en su Consejo Directivo. Madrid se constituyó en la sede central del organismo, con las figuras de Duhalde y Roca como referencias indiscutidas, seguida por las delegaciones de París y México DF. Sus ramificaciones, sin embargo, alcanzaron también otros países europeos y Estados Unidos (Guest, 1997; Franco, 2008; Yankelevich, 2010). En este contexto, se elaboró el borrador del informe, redactado por Duhalde y Roca en el exilio madrileño. Su publicación bajo el formato de libro fue posible gracias a la solidaridad de un cineasta vasco con el que entraron en contacto los miembros de la CADHU, Elías Querejeta, quien financió de su bolsillo la primera edición de marzo de 1977.

Los relatos de los sobrevivientes ocupaban un lugar destacado en Argentina: Proceso al Genocidio, tal como lo dejaba entrever su agrupamiento en una sección separada. Siguiendo la tendencia del primer año de dictadura, "Testimonios y denuncias" reunía alrededor de una decena de relatos de sobrevivientes de CCD con otros tantos de detenidos en las cárceles legales. Había, además, algunos testimonios de personas que habían atravesado el cautiverio clandestino durante el último año del gobierno de María Estela Martínez de Perón. La decisión de incluir también estos relatos

\footnotetext{
30 Para una historia del PROA, véase Rot (2015).

31 Memoria Abierta, Entrevista a Manuel Gaggero, Buenos Aires, 17 y 24 de noviembre y 19 de diciembre de 2003; Rot (2015).

32 En la centralización de la información recibida de parte de las organizaciones armadas jugó un rol central Ignacio Ikonicoff, quien se encargó de hacerla salir del país cuando una parte de los miembros de la CADHU se instaló en el exterior. Ikonicoff sería secuestrado y desaparecido junto a un número importante de miembros del organismo del grupo proveniente del PROA en la llamada "Masacre de Marcos Paz", ocurrida entre el 11 y 12 de junio de 1977 (Rot, 2015).

33 El estatuto del organismo hacía énfasis en la necesidad de lograr la "ampliación y profundización de la denuncia ante Foros Internacionales" (CADHU, Estatuto, 10 de diciembre de 1976).
} 


\section{Rodrigo González Tizón}

reforzaba la postura del organismo respecto a las continuidades que existían entre la represión dictatorial y la del último tramo del gobierno peronista.

Los testimonios presentaban una enorme heterogeneidad en cuanto a su formato, extensión y condiciones de producción. El parecido con los relatos del primer año de dictadura también se evidenciaba en su contenido, centrado en los componentes fácticos de la experiencia del cautiverio clandestino, y en la organización del relato según un criterio cronológico. Estas similitudes no eran casuales: más de la mitad de los testimonios del informe de la CADHU habían sido incluidos ya en los documentos publicados por AI, el COSPA y el CAIS durante 1976, evidenciando los lazos que unían a los diversos representantes del activismo antidictatorial en el exilio. Uno de los relatos era el de María del Socorro Alonso, quien había hecho llegar su relato a la CADHU desde el penal de Devoto ${ }^{34}$.

La diferencia con los relatos previos radicaba sobre todo en su encuadre. El informe de la CADHU, a tono con la impronta militante del organismo, ofrecía una interpretación en clave socioeconómica de la represión en la Argentina y de la "resistencia popular y obrera" a ella ${ }^{35}$. Organizado en cinco grandes apartados, el escrito se proponía también una tipificación de las conductas criminales estatales, comenzando por un análisis de la estructura y el funcionamiento del "Estado represor"36. Esto era seguido de una exposición de los distintos grupos profesionales, políticos, sociales, confesionales y nacionales- que eran víctima del "Terrorismo de Estado". Una sección completa del informe estaba dedicada a la represión sobre la clase obrera, que constituía para la CADHU el blanco prioritario de una persecución orquestada por los representantes del capitalismo financiero mundial. Todo este análisis funcionaba como metatexto de los testimonios que, en apariencia, no contaban con ninguna mediación.

Una lógica similar, aunque con un grado mayor de intervención sobre los relatos, animaba al informe de AI, presentado a través de una conferencia de prensa en Londres el 23 de marzo de 1977. A diferencia del escrito de la CADHU, el documento estaba construido desde una discursividad exclusivamente humanitaria: su objetivo era mostrar "la situación de los derechos humanos en la Argentina"37. El rechazo hacia toda forma de violencia se expresaba desde la introducción del informe, donde se reseñaban los principales "actos de violencia" realizados por las organizaciones armadas luego del golpe de Estado ${ }^{38}$. Siguiendo esta línea, en las conclusiones se planteaba que la represión "también afecta a ciudadanos inocentes"39. Aun así, el grueso del documento estaba dedicado a la denuncia de la represión estatal, y en función de ella era convocada la palabra de los sobrevivientes. La presencia de dos testimoniantes del informe, Máximo Victoria y Enrique Rodríguez Larreta, en la

\footnotetext{
${ }^{34}$ Memoria Abierta, Entrevista a María del Socorro Alonso, Buenos Aires, 24 de julio de 2001.

35 CADHU, op. cit., 1977, p. 11.

36 Estas secciones eran "Estructura del Estado represor", "El Terrorismo de Estado", "La represión obrera: razón de Estado”, “Epílogo” y “Testimonios y denuncias” (Ibidem).

37 Amnistía Internacional, op. cit., 1977, p. 10.

38 Ibidem, pp. 13-14.

39 Ibidem, p. 67.
} 


\section{“Los desaparecidos empiezan a hablar": una aproximación histórica a la producción testimonial de los sobrevivientes de la dictadura argentina desde el exilio (1976-1983)}

conferencia de presentación sugería el valor que el organismo le otorgaba a su palabra (Gutman, 2015).

El formato de inclusión de los testimonios era distinto al del escrito de la CADHU. Los relatos no eran reproducidos de manera íntegra, sino por fragmentos o parafraseados por el organismo. Tampoco estaban agrupados en un apartado específico. Se incorporaban al texto general del documento mediante una fórmula que reponía los datos biográficos básicos del sobreviviente: "Isabel Gamba de Negrotti, de 27 años de edad y maestra de jardín de infantes, fue secuestrada de su domicilio junto con su esposo y llevada a la Comisaría 39 de Villa Urquiza, en Buenos Aires" ${ }^{40}$. El testimonio de Patrick Rice, uno de los más extensos del informe, lo presentaba como un "cura obrero irlandés"41. La presentación de los sobrevivientes a partir de sus datos identitarios básicos mostraba a estos hombres y mujeres desde sus atributos humanos esenciales y no de sus filiaciones políticas. Este recurso, sumado al énfasis que hacían los relatos en las torturas vistas y vividas, resaltaba la condición de víctimas de los testimoniantes (Crenzel, 2008).

Las voces de los sobrevivientes emergían también, de manera indirecta, en el pasaje del informe en el que AI enumeraba las dificultades para obtener información sobre los "centros de detención no oficiales", nombre utilizado para referir a los $\mathrm{CCD}^{42}$. El organismo sostenía que "a menudo, los prisioneros permanecen encapuchados o con una venda sobre los ojos durante todo el tiempo de su detención" y que "aquellos que tienen la fortuna de ser puestos en libertad experimentan gran temor de hacer declaración pública alguna"43. Los detalles no podían tener otra fuente que los propios sobrevivientes. La decisión de AI de hacer explícita la distinción entre esos "centros de detención no oficiales" y los penales oficiales podría ser tomada como indicio de una incipiente separación entre ambas prácticas represivas ${ }^{44}$.

Los informes de la CADHU y AI circularon pronto por diferentes países de Europa Occidental y América. Uno de sus canales de difusión fue la prensa, que tempranamente posó su mirada en los documentos y en quienes habían testimoniado en ellos: periódicos de Inglaterra, España y México, entre otros países, publicaron artículos alusivos a los informes y/o realizaron entrevistas a los testimoniantes ${ }^{45}$. Para el caso de AI, otra vía de difusión fueron los propios

\footnotetext{
40 Ibidem, p. 51. El informe ofrece varios ejemplos de esta fórmula (pp. 50-52).

41 Ibidem, p. 41.

42 Ibidem, p. 43.

43 Idem.

${ }^{44}$ A pesar de las dificultades esbozadas, el informe ofrecía los nombres de diecisiete "centros de detención no oficiales" distribuidos en cuatro provincias (Amnistía Internacional, op. cit., 1977, pp. 43-44).

45 Pocos días después de la conferencia de prensa en Londres, The Sunday Times publicó una entrevista con Rodríguez Larreta (Gutman, 2015: 118). En España, El País publicó una nota alusiva a la aparición del libro de la CADHU bajo el título "El genocidio argentino". El artículo reservaba un párrafo para referirse al apartado con los testimonios ("El genocidio argentino", El País, 10 de abril de 1977). En México, los informes de Amnistía Internacional y de la CADHU merecieron notas en diversos periódicos (El Día, "Impera en la Argentina un Régimen de Terrorismo de Estado: la CADHU”, 19 de marzo de 1977 "Amnistía Internacional Denuncia que hay en Argentina 6 mil Presos
} 


\section{Rodrigo González Tizón}

sobrevivientes quienes, aprovechando el anclaje transnacional del organismo, ofrecieron sus relatos en distintos países y ante públicos de diversa índole ${ }^{46}$. Este mismo espíritu por trascender las fronteras nacionales, y también indicio de su circulación durante la época, fueron las múltiples traducciones que se hicieron de los documentos ${ }^{47}$.

La articulación con el Alto Comisionado de las Naciones Unidas para los Refugiados (ACNUR) y diversos gobiernos que se mostraron receptivos a los exiliados contribuyó a engrosar el circuito testimonial de AI. Las gestiones realizadas en favor de los "presos de conciencia" ante el organismo dependiente de la ONU y con representantes políticos de los potenciales países de acogida resultaron fundamentales para que muchos sobrevivientes obtuvieran el refugio. Una vez en el exilio, muchos de ellos aportaron sus testimonios a AI que, luego, los incorporó a sus denuncias públicas. La mayoría de estos sobrevivientes había abandonado la Argentina a través de Brasil, aprovechando las facilidades que ofrecían los distintos pasos fronterizos entre ambos países. Este fue el caso, por ejemplo, de Ana María Careaga, secuestrada por más de tres meses en el CCD "El Atlético", en centro de la Ciudad de Buenos Aires. Su militancia en la Juventud Guevarista no impidió que ACNUR y AI tomaran su caso y lograran, luego de una escala en Río de Janeiro, su refugio en Suecia, donde testimonió el 7 de febrero de $1978^{48}$.

En las antípodas de esta orientación humanitaria se situaron los testimonios de sobrevivientes difundidos en el exilio por Montoneros durante el año 1978. Su publicación se hizo bajo el sello del flamante Movimiento Peronista Montonero (MPM), espacio político creado en Roma en abril de 1977 para aglutinar a las diversas expresiones del peronismo revolucionario que proliferaban dentro y fuera de la Argentina. Los testimonios vieron la luz en un momento en el que las iniciativas de denuncia cobraban fuerza entre los militantes montoneros en el exilio (Confino, en prensa). Esta actividad se apoyaba en las estructuras y contactos gestados durante el bienio previo al golpe, cuando el aumento de la represión paraestatal impulsó a varios militantes a iniciar el éxodo de la Argentina (Yankelevich, 2010). La CADHU ofrecía sólo uno ejemplo de esos vínculos, que abarcaban a diversas

\footnotetext{
sin Proceso Legal y 5 mil Desaparecidos', 24 de marzo de 1977; Excelsior, “Testimonio de un uruguayo torturado en Argentina, 14 de abril de 1977).

46 Pocos días después de la publicación del documento, el 1 de abril, Rice ofreció su relato del cautiverio en una sesión especial del Parlamento británico junto a representantes de AI. Del mismo modo, el 26 de septiembre, Victoria participó de la conferencia de prensa en Madrid con la que el organismo presentó la versión en español del documento (Gutman, 2015: 125 y 119). Este recorrido de los sobrevivientes pone de relieve el peso de la dimensión transnacional en el sentido en que lo entienden Roniger y Sznajder (2013), esto es, como una cuarta dimensión que supera la relación tripartita entre exiliados, país receptor y país expulsor y que es condición de posibilidad para la difusión de las denuncias.

${ }^{47}$ Se realizaron traducciones completas de Argentina: Proceso al Genocidio al francés y alemán, y parciales al inglés, italiano y holandés (CADHU, Argentina: Proceso al Genocidio, Buenos Aires: Colihue, 2014). El informe de AI fue publicado en inglés, español y alemán (Gutman, 2015).

${ }^{48}$ El testimonio de Ana María Careaga adquiría una relevancia particular debido a que, poco después de su liberación, sería secuestrada su madre, Esther Ballestrino, fundadora de Madres de Plaza de Mayo.
} 


\section{“Los desaparecidos empiezan a hablar": una aproximación histórica a la producción testimonial de los sobrevivientes de la dictadura argentina desde el exilio (1976-1983)}

organizaciones de signo político heterogéneo distribuidas por una amplia geografía (Franco, 2008; Jensen, 2010).

México, donde cobraron forma las estructuras más tempranas de solidaridad y denuncia vinculadas al peronismo revolucionario (Acha, 2010; Yankelevich, 2010), fue el lugar donde se publicó el primero de los "testimonios montoneros". El 18 de enero de 1978, en una conferencia de prensa en la capital de ese país, Tulio Valenzuela narró su cautiverio en el CCD "Quinta de Funes" y el plan del Ejército para secuestrar a la conducción montonera exiliada. La versión taquigráfica del relato, distribuida entre la prensa mexicana, tenía una introducción a cargo de Montoneros que estaba teñida por la discursividad revolucionaria y funcionaba como marco del testimonio ${ }^{49}$. El mismo espíritu atravesaba todo el relato, en el que se reiteraban las referencias a la "lucha popular" y al "pueblo en la resistencia" 50 y donde se interpretaba el enfrentamiento entre Montoneros y la dictadura en los términos de una "guerra"51. La descripción del cautiverio, acotada, era subsidiaria de la valoración ético-política del comportamiento de los secuestrados, con alusiones al "quiebre de cuadros" o a los "traidores"52. Denuncia de la represión y disciplinamiento interno parecían ir de la mano en el testimonio de Valenzuela.

El tono cambiaba ligeramente en los otros dos relatos, a cargo de Horacio Maggio y Jaime Dri. El primero fue producido desde la clandestinidad en la Argentina y vio la luz en abril de 1978, cuando la atención internacional estaba posada en el país debido a la proximidad del Mundial de fútbol ${ }^{53}$. El testimonio de Dri se presentó en una conferencia de prensa en París durante septiembre del mismo año. En ambos, la retórica revolucionaria predominante dejaba algunos resquicios para la denuncia de las atroces condiciones de cautiverio, "dignas de la época anterior a la Asamblea del año XIII" 54 , y para la caracterización de las acciones represivas no ya como episodios bélicos, sino como "terrorismo de Estado" 55 y "violaciones a los derechos humanos"56. Otro indicio de la incorporación de ciertas notas de la denuncia humanitaria internacional eran los destinatarios de los testimonios: Maggio envió copias de su testimonio, entre otros, a la $\mathrm{ONU}, \mathrm{AI}$, agencias de prensa extranjeras y

\footnotetext{
49 Allí se definía la acción de Valenzuela como una "heroica y brillante maniobra de contrainteligencia" que le había permitido "burlar al enemigo que lo tenía prisionero" (MPM, Testimonio del compañero Tulio Valenzuela sobre la campaña de atentados en el exterior de la dictadura de Videla, 1978, p. 1).

50 Ibidem, pp. 7 y 8.

51 Ibidem, pp. 3 y 7.

52 Ibidem, p. 3.

53 El evento deportivo, por su relevancia internacional, generó una fractura al interior de la comunidad de exiliados entre quienes pensaban que debía impedirse su realización -y aquellos que lo veían como una oportunidad para que la prensa extranjera conociera de primera mano los crímenes de la represión (Franco, 2008; Jensen, 2010).

54 Maggio, Horacio Domingo. Testimonio, abril de 1978, p. 2.

55 MPM, Testimonio de Jaime Dri, s/l, septiembre de 1978, pp. 1 y 8.

56 Ibidem, p. 5.
} 


\section{Rodrigo González Tizón}

representaciones diplomáticas diversas ${ }^{57}$. A la conferencia de prensa de Dri, que encabezó su relato "a la opinión pública nacional e internacional", asistieron representantes del Partido Socialista Francés (PSF), incluido su presidente, François Mitterrand 58 .

Paralelamente a la publicación de los "testimonios montoneros", se gestaba en Brasil otro polo de difusión de relatos de sobrevivientes con una impronta política diferente a la de la organización armada peronista. Su eje sería el Comité de Defensa de los Derechos Humanos para el Cono Sur (CLAMOR), creado en San Pablo a comienzos de 1978 con el apoyo del cardenal Don Paulo Evaristo Arns y de la Comissão Arquidiocesana de Pastoral dos Direitos Humanos e Marginalizados de esa ciudad59. A tono con estos apoyos, el organismo declaraba "tener por objetivo la defensa de los derechos humanos en América Latina, especialmente en los países del Cono Sur" desde una perspectiva "cristiana, ecuménica, sin filiación partidaria" y con objetivos "humanitarios" 60 . Esta orientación política dejaría su marca en el circuito testimonial de CLAMOR.

Desde el inicio, el organismo se planteó como un espacio regional para desarrollar redes de solidaridad y denuncia que conectaran a los países latinoamericanos bajo dictadura (Catoggio, 2016). En el caso argentino, buena parte de la solidaridad se concentró en la ayuda a quienes escapaban rumbo al exilio. Durante su permanencia en Brasil, CLAMOR los resguardaba de los servicios de inteligencia locales (Serra Padrós, 2014) y facilitaba su acercamiento a organismos especializados en la problemática de los refugiados, en particular el ACNUR y AI. La articulación con estos organismos se dio, también, al nivel de la circulación de testimonios. Así ocurrió, por ejemplo, con Máximo Victoria, cuyo relato del cautiverio se había incluido en el informe de AI. En julio de 1978, el Boletín de CLAMOR reprodujo su testimonio en un artículo sobre la represión a científicos -Victoria era físico y trabajaba en la CONEA-, evidenciando los nexos entre ambos circuitos testimoniales ${ }^{61}$.

En su primer boletín, publicado en junio de 1978, el organismo incluyó un artículo titulado "El clamor de los campos de concentración", donde se describían las condiciones de cautiverio en los CCD argentinos ${ }^{62}$. La denominación empleada daba cuenta de la difusión que había alcanzado el campo léxico del Holocausto entre los denunciantes de la dictadura. La información para confeccionar el artículo provenía

\footnotetext{
57 Maggio, op. cit., p. 7. El propio Maggio dio una entrevista desde la clandestinidad al periodista Richard Bourdeaux, subdirector de la agencia de noticias norteamericana Associated Press en Argentina.

${ }^{58}$ Bonasso, M., Recuerdo de la muerte, Buenos Aires: Planeta, 1994 [1984], p. 438.

${ }^{59} \mathrm{El}$ impulso que llevó a la fundación de CLAMOR surgió de la periodista Jan Rocha, del abogado Luiz Eduardo Greenhalgh y del pastor protestante Jaime Wright (Catoggio, 2016).

${ }^{60}$ CLAMOR, Boletín, Año I, Nro. I, junio de 1978, p. 1.

${ }^{61}$ CLAMOR, Boletín Nro. 2, julio de 1978. La orientación eminentemente humanitaria de CLAMOR no le impidió recibir testimonios de circuitos testimoniales menos afines a su posicionamiento político. El archivo del organismo contiene, por ejemplo, varios relatos producidos en el seno de la CADHU (Tolentino, en prensa).

${ }^{62}$ CLAMOR, Boletín Nro. 1, junio de 1978.
} 


\section{“Los desaparecidos empiezan a hablar": una aproximación histórica a la producción testimonial de los sobrevivientes de la dictadura argentina desde el exilio (1976-1983)}

de "exiliados en tránsito por Brasil" que, por el tipo de datos aportados, sólo podían ser personas que habían experimentado en carne propia el cautiverio clandestino. La referencia a ellos simplemente como "exiliados" -algo que, por otro lado, también eran- podría considerarse un indicio de la falta de consenso en torno a considerar a los sobrevivientes de los CCD como una categoría de víctima en sí misma, lo que se expresaba en la ausencia de un término específico para nombrarlos.

A tono con la inclinación política del organismo, los relatos reproducidos por CLAMOR denunciaban los crímenes dictatoriales desde un enfoque humanitario. El foco estaba puesto, como sucedía con AI, en resaltar la atrocidad del cautiverio en los CCD, cuyas condiciones eran definidas como "inhumanas y de degradación y terror". Este tipo de caracterizaciones generales eran acompañadas por descripciones minuciosas de los tormentos. El primer boletín del organismo, por ejemplo, ofrecía un listado detallado de las vejaciones aplicadas a los cautivos en los CCD: "sus manos y pies están atados o encadenados la mayor parte del tiempo", "no existe higiene", "la comida es servida en latas o platos no lavados", "los prisioneros son amontonados en galpones", "no existe cuidado médico"63.

Paralelamente a la conformación del circuito testimonial de CLAMOR, en la Argentina comenzaba a disminuir el ritmo de los secuestros y a aumentar la cantidad de liberaciones en los CCD. Estos cambios se relacionaban con el impacto que habían tenido sobre la Junta Militar ciertas transformaciones de la coyuntura política internacional. A las sanciones que el gobierno de Carter impuso a la dictadura se sumó la confirmación, a fines de 1978, de una visita de la CIDH a la Argentina, programada para el año siguiente. En un contexto donde el principal elemento de cohesión interna de la comunidad castrense, el denominado "consenso antisubversivo" (Canelo, 2008), languidecía ante el aniquilamiento de las principales expresiones políticas disidentes, estas modificaciones en el ámbito internacional profundizaron las tensiones internas a las Fuerzas Armadas en relación al rumbo que debía seguir la "lucha contra la subversión". El triunfo de sector "politicista", partidario de un progresivo abandono de los métodos represivos clandestinos en favor de los legales, fue decisivo en el giro del accionar castrense.

La formación de un circuito testimonial estructurado en torno al partido Vanguardia Comunista (VC) estuvo estrechamente relacionada con estos cambios en la escena política argentina. Esta fuerza de orientación maoísta, ajena a la lucha armada, había optado por mantener al grueso de sus militantes en el país a pesar del clima de persecución existente (Celentano, 2005). No obstante, debido a la insistencia de algunos dirigentes partidarios, se había decidido establecer a unos pocos miembros de su Comité Central en Francia a mediados de 1976. El objetivo era desarrollar redes de denuncia partidarias en Europa, tarea que resultó exitosa: además de peregrinar por las sedes de los organismos internacionales de derechos humanos, entablaron vínculos con actores políticos de diverso signo ideológico del espectro

63 Ibidem, p. 3. 


\section{Rodrigo González Tizón}

partidario francés y con diferentes organizaciones de exiliados locales ${ }^{64}$. Esos contactos serían claves cuando, dos años después, el partido se convirtió en blanco de la represión del Ejército 65 .

El circuito testimonial de VC se nutrió de los testimonios de un conjunto de militantes sobrevivientes del CCD "El Vesubio" que, secuestrados entre julio y agosto de 1978, fueron luego legalizados en distintos penales. Una vez en libertad, a mediados de 1979, se exiliaron en Europa. Desde allí, aprovechando las redes partidarias consolidadas en el extranjero, difundieron sus relatos del cautiverio clandestino. A contracorriente de la orientación revolucionaria del partido, los testimonios -heterogéneos en cuanto a formato y contexto de producciónasumieron una inclinación humanitaria que ponía el foco en una descripción fáctica de la experiencia de cautiverio desprovista de toda valoración política. El estilo era coherente con el universo de relaciones de VC en el exilio, donde dentro del cual destacaban AI, ACNUR, las iglesias protestantes y distintas fuerzas de la socialdemocracia europea, quienes garantizaron la difusión de los relatos. Por consiguiente, no es extraño que ninguno de los sobrevivientes del partido ofreciera su testimonio a la CADHU, cuyos nexos con las organizaciones armadas eran conocidos en el destierro argentino.

El bienio posterior al primer aniversario del golpe de Estado fue el período en que se consolidó el mapa testimonial de los sobrevivientes en el exilio. La mayor cantidad de relatos en circulación fue propiciada por una serie de entidades heterogéneas en su orientación política pero que coincidían en el impulso de visibilizar la experiencia del cautiverio clandestino, en torno a las cuales se estructuraron distintos circuitos de testimonios. Las diferencias que existían entre cada una de ellas repercutieron en el encuadre y el contenido de los relatos y favorecieron u obstaculizaron los intercambios entre los distintos circuitos que, sin embargo, no funcionaron como compartimentos estancos. Se sentaron así las bases para que, en la coyuntura favorable a la denuncia habilitada por la visita de la CIDH, los relatos de los sobrevivientes conquistaran definitivamente el espacio público exilar. El hito inicial de esta nueva etapa fue el llamado "testimonio de París".

\section{La "era del testigo" en dictadura: consagración pública, nuevos formatos y polémica}

El 12 de octubre de 1979, tres militantes montoneras sobrevivientes de la ESMA Ana María Martí, Sara Solarz y Alicia Milia- se presentaron ante la Asamblea Nacional Francesa para relatar su cautiverio a manos de la Marina ${ }^{66}$. La conferencia

\footnotetext{
64 “C. R.", entrevista con el autor, CABA, 4 de mayo de 2019.

65 Según este dirigente, "fuimos armando una estructura que cuando llega gente (...) tenías una estructura armada para que las reciban y metan todo el tema de la denuncia". ("C. R.", entrevista con el autor, op. cit.).

${ }^{66}$ CADHU, “Testimonios de los sobrevivientes del genocidio en Argentina”, París, octubre de 1979.
} 


\section{"Los desaparecidos empiezan a hablar": una aproximación histórica a la producción testimonial de los sobrevivientes de la dictadura argentina desde el exilio (1976-1983)}

de prensa estuvo encabezada por el presidente de la Comisión Interparlamentaria de Derechos Humanos, el político liberal Bernard Stasi, y contó con la anuencia del máximo mandatario francés, Giscard D’Estaing. Las mujeres, además, contaron con la protección de la custodia personal de Mitterrand. El testimonio fue patrocinado por la CADHU, aunque diversos protagonistas y estudiosos del período sugieren también la participación activa de Montoneros en las gestiones previas con los actores locales (Franco, 2008; Jensen, 2010) ${ }^{67}$. Dada la trayectoria política de las testimoniantes y los nexos del organismo con la organización armada peronista, la hipótesis no resulta descabellada.

El relato de las tres sobrevivientes tuvo una difusión veloz en el exilio, reflejada en distintos medios de prensa ${ }^{68}$. Esta amplia resonancia se debió, en parte, al lugar elegido para la presentación: Francia era una suerte de "patria de los derechos humanos" y una caja de resonancia de la política occidental (Franco, 2008). Otros aciertos estratégicos fueron la decisión de realizar la conferencia de prensa en el Parlamento francés y la búsqueda de apoyos entre referentes políticos locales de diversas procedencias ideológicas. A estos factores internos se sumó, con un rol determinante, el efecto de la visita de la CIDH a la Argentina, ocurrida durante el mes anterior a la realización del testimonio. La intervención del organismo había encendido el interés de la comunidad internacional por la situación de los derechos humanos bajo el gobierno de la Junta Militar (Jensen, 2010). Todo esto convirtió a la conferencia de prensa de las tres sobrevivientes de la ESMA en un verdadero hito de la denuncia de su tiempo.

El "testimonio de París" condensó -y también estimuló- una serie de transformaciones en los modos de denominación pública de los sobrevivientes y en los formatos de difusión de sus relatos que se generalizaría en el exilio a partir de 1979. En cuanto a lo primero, el uso del término "sobreviviente" marcó una novedad en las categorías que designaban a quienes salían con vida de los CCD. La noción fue empleada por la CADHU en el título del relato $\mathrm{y}$, también, por las propias testimoniantes, quienes hicieron de ella una definición identitaria: "Somos tres mujeres argentinas, unas de las pocas sobrevivientes de un campo de concentración militar de nuestro país", afirmaron ${ }^{69}$. La nueva denominación establecía un límite preciso -y mayor del existente en la práctica- con el preso político, dando lugar a una nueva categoría de víctima.

\footnotetext{
${ }^{67} \mathrm{Al}$ ser consultada por el testimonio de París, Alicia Milia sostuvo que "lo bancó la CADHU, [pero] yo creo que sí lo negoció con la organización Montoneros" (entrevista con el autor, Buenos Aires, 17 de junio de 2019).

${ }^{68}$ El 14 de octubre de 1979, a raíz de la denuncia de las tres sobrevivientes de la ESMA, el diario francés Liberátion denunció en tapa la presencia de un miembro del grupo de tareas en el Centro Piloto bajo el título "Un torturador argentino designado en París". También dio cuenta del testimonio el periódico español El País, que identificaba a sus autoras como "Las tres mujeres supervivientes de los desaparecidos de la Argentina" (El País, 13 de octubre de 1979). Dos meses después, Presencia Argentina, publicación del Centro Argentino de Madrid, reprodujo el relato en un artículo titulado "Testimonio de la Escuela de Mecánica" (Nro. 2, diciembre de 1979).

${ }^{69}$ CADHU, op. cit., 12 de octubre de 1979, p. 5.
} 
La noción trascendió a la CADHU. Se difundió por distintos circuitos testimoniales y países a través de una diversidad de actores, incluidos los propios sobrevivientes, lo que podría tomarse como un indicio de su aceptación ${ }^{70}$. Aun así, el término debió convivir con otros que también se utilizaban para denominar públicamente a quienes salían con vida de los CCD. Las expresiones vinculadas a la prisión política se mantuvieron vigentes, aunque en menor medida, a pesar de la diferenciación que se había establecido con el secuestro clandestino. Otro término que circuló en la época, reproducido incluso en los testimonios, fue el de "liberados"71. Tampoco faltaron las referencias a los sobrevivientes como "reaparecidos" o, incluso, como "desaparecidos" a secas ${ }^{72}$. La multiplicidad de términos en circulación, que se mantuvo hasta finales del período dictatorial -e, incluso, en los inicios de la democracia-, sugiere cierta pervivencia en la inestabilidad de las categorías ${ }^{73}$.

Con la versión impresa del testimonio de París, publicada en paralelo a la conferencia de prensa, apareció un nuevo modelo de relato que alcanzaría amplia difusión en el exilio ${ }^{74}$. Hasta entonces, las voces de los sobrevivientes habían circulado mayoritariamente en el marco de publicaciones más amplias, como había sucedido con los relatos de Argentina: Proceso al Genocidio o del informe de AI. A partir de la publicación del testimonio de las tres mujeres de la ESMA, esa modalidad de difusión de la palabra de los sobrevivientes coexistió con otra en la que el relato del cautiverio daba lugar a un documento específico. Este nuevo modelo de

\footnotetext{
${ }^{70}$ Así se presentaban, por ejemplo, los autores de un testimonio publicado por AI en febrero de 1980: "Somos dos sobrevivientes de los campos de concentración en Argentina" (Amnistía Internacional, Testimonios sobre campos secretos de detención en Argentina, Londres: Publicaciones de Amnistía Internacional, 1980, p. 2). De igual modo, los artículos que animaron la polémica por el contenido de los testimonios en México se titularon sucesivamente "Los testimonios de los sobrevivientes" (Controversia, Año II, número 9-10, México, diciembre de 1980), "Los sobrevivientes de los testimonios" (Cuadernos de Marcha, México, enero-febrero de 1981) y "Tres sobrevivientes responden" (Controversia, Año II, Nro. 14, agosto de 1981, p. 29.). En diciembre de 1983, CLAMOR publicó un testimonio bajo el título "Sobrevivientes de 'La Cacha' se reúnen en Brasil" (CLAMOR, Boletín Nro. 15, diciembre de 1983, p. 13).

${ }^{71}$ En un pasaje de su testimonio a la CADHU, Graciela Daleo y Andrés Castillo se referían a sí mismos como "liberados de los campos de concentración" (Testimonio de Graciela Daleo y Andrés Castillo, Madrid,18 de febrero de 1982, p. 22).

72 "Campo de concentración clandestino denuncian desaparecidos argentinos", El Día, México, 17 de noviembre de 1983; "Testimonio de un desaparecido", Resumen de la actualidad argentina, nro.78, 20 de diciembre de 1982; "Testimonio de una desaparecida al diario madrileño Pueblo", El Día, México, 16 de marzo de 1983; "Los desaparecidos empiezan a hablar", Siete Días, México, 19 de octubre de 1983.

${ }^{73}$ Esta inestabilidad de las categorías no se planteó sólo respecto de quienes habían salido con vida de los CCD. En términos generales, se hizo extensiva al conjunto del fenómeno represivo de la última dictadura (Franco, 2019) y llegó a su fin con la publicación del informe de la CONADEP en noviembre de 1984 (Crenzel, 2008).

74 Tres semanas antes del testimonio en la Asamblea Nacional Francesa, Nilda Orazi, sobreviviente de la ESMA y del CCD "Club Atlético", narró su cautiverio en una conferencia de prensa en París auspiciada por el COSOFAM. La versión escrita del relato presentaba una estructura similar a la del testimonio de las tres sobrevivientes de la ESMA. El parecido se explicaba por la participación de Orazi en las reuniones preparatorias de este último, del que finalmente decidió no participar presentando su relato de manera independiente y al margen de la CADHU. (Graciela Daleo, entrevista con el autor, CABA, 4 de junio de 2019). En consecuencia, es posible pensar a ambos testimonios como resultado de un mismo proceso de producción.
} 


\section{"Los desaparecidos empiezan a hablar": una aproximación histórica a la producción testimonial de los sobrevivientes de la dictadura argentina desde el exilio (1976-1983)}

testimonio aspiraba a recuperar la "experiencia integral" del CCD: la descripción fáctica del cautiverio era complementada con una reconstrucción de las lógicas, dinámicas y espacialidades del dispositivo concentracionario.

Este formato alcanzó su máxima expresión en la "serie CADHU” (González Tizón, 2016), un conjunto de testimonios publicados bajo el sello del organismo en diversas plazas del destierro argentino entre 1979 y 1983. Su extensión superaba con creces la de sus predecesores. El largo iba en consonancia con el nuevo perfil de testimoniante: en su mayoría, eran personas liberadas hacia fines de 1978 o principios de 1979 y que habían atravesado un cautiverio prolongado, de entre uno y dos años. Sus trayectorias políticas o su expertise técnica habían determinado su incorporación a diversas modalidades de trabajo forzado durante el cautiverio, como el "proceso de recuperación" de la ESMA, que implicaban condiciones de reclusión menos estrictas y contactos fluidos con los represores ${ }^{75}$. Estas circunstancias les habían permitido acceder a un conocimiento de los actores y la dinámica del CCD inalcanzable para el resto de los secuestrados. La combinación de este saber y de los capitales políticos disponibles -que favorecieron los contactos con las redes de denuncia en el exilio- generó las condiciones para la confección de relatos de una envergadura desconocida hasta entonces.

Los testimonios se distinguían también por su estructura, que traslucía las múltiples mediaciones sobre la palabra de los sobrevivientes. La mayoría comenzaba con una introducción a cargo de la CADHU donde se desarrollaba una caracterización de la dictadura en una clave similar a la del informe de 1977. Luego, distintas secciones temáticas reemplazaban al ordenamiento puramente cronológico de los primeros testimonios. El nuevo criterio iba de la mano con una lógica jurídica reconocible en el esfuerzo de tipologización y la exposición a partir de "casos"76. La incorporación de planos del CCD aportaba referencias "objetivas" a la narración, otro rasgo distintivo del testimonio judicial (Pollack, 2006). Los listados de secuestrados y secuestradores, a su vez, permitían distinguir entre víctimas y victimarios y adjudicar, así, las responsabilidades por los crímenes (Tello, 2015). Más allá de la

\footnotetext{
75 Para una descripción del "proceso de recuperación" de la ESMA, véase Feld y Franco (2019).

${ }^{76}$ Un ejemplo concreto, tomado del relato de Alberto Girdondo permite ilustrar la estructura de la serie "CADHU": "Datos personales del testimoniante"; "Cronología de los hechos"; "El Grupo de Tareas 3.3.2. Antecedentes de su formación"; "Orígenes del 3.3.2"; "Carácter institucional de la represión"; "Descripción del centro de detención de la ESMA"; "Sótano, planta baja, dorado, altillo o "capucha"; "Organización y estructura del GT 3.3.2"; "Inteligencia-Operaciones"; "Logística"; "Guardias"; "Los secuestros"; "Los interrogatorios"; "Destino de los secuestrados de la ESMA. Los hechos de los cuales tuve conocimiento directo"; "Versiones obtenidas de los miembros del GT"; Conclusiones"; "Los secuestrados puestos en libertad"; "Secuestradas embarazadas"; "Secuestro de quince personas de una iglesia"; "Abogados Díaz Lestren y Pesci"; "Norma Arrostito"; "Horacio Maggio"; "Operaciones de secuestro en el exterior del país"; Personas que integraron el GT 3.3.2. Oficiales de Marina"; "Personal de Policía Federal - Personal de la P.N.M"; "Otras personas que estuvieron secuestradas en la ESMA y cuyo paradero desconozco" (CADHU, Testimonio sobre el centro de detención secreto de la Escuela de Mecánica de la Armada, en Buenos Aires Argentina. Testimoniante: Alberto Girondo, Ginebra, febrero de 1982. Archivo de Familiares de Detenidos y Desaparecidos por Razones Políticas, disponible en Memoria Abierta).
} 


\section{Rodrigo González Tizón}

tradición jurídica de la CADHU, la cuestión asumía un sentido estratégico en una coyuntura donde se percibía como factible un eventual proceso penal a los autores de la masacre (Jensen, 2019).

La construcción de la denuncia en base a distintos "casos" remitía al formato empleado, entre otros organismos internacionales, por la CIDH. La entidad con sede en Washington había recibido denuncias sobre la represión ilegal desde los inicios de la dictadura. Una parte de ellas había sido realizada directamente por los sobrevivientes exiliados. Estas presentaciones motivaron reclamos de la CIDH ante la Junta Militar que se organizaron a partir de "casos" que podían ser individuales o colectivos, si se trataba de familiares o personas secuestradas en un mismo hecho represivo. Algunos de esos reclamos fueron incluso difundidos públicamente por el organismo. Así ocurrió con Patrick Rice, por ejemplo, quien aprovechó las facilidades que le ofrecía su doble condición de sacerdote y extranjero para denunciar su secuestro en Estados Unidos ${ }^{77}$. Su testimonio, que ya había recorrido múltiples instancias y otras tantas geografías, fue incluido como parte del "caso 2450" en el Informe Anual de $1978^{78}$.

La influencia de los modelos de denuncia empleados por las entidades transnacionales se aceleró con la visita de la CIDH y terminó de consolidarse con la creación, en febrero de 1980, del Grupo de Trabajo sobre Desapariciones Forzadas e Involuntarias de la ONU, cuya sede estaba en Ginebra79. Este organismo se situó a la cabeza del conjunto de organizaciones radicadas en la capital suiza que recibieron los testimonios de los sobrevivientes ${ }^{80}$. Su papel fue central en la estandarización de las denuncias según los criterios del derecho humanitario internacional al proveer los modelos para la toma y presentación de los reclamos (Crenzel, 2008). Este proceso abarcaba también los lenguajes con los que se daba cuenta de la violencia estatal, favoreciendo un progresivo desplazamiento de la narrativa revolucionaria por otra centrada en las víctimas (Franco, 2008). De este modo, al mismo tiempo que ofreció las condiciones de posibilidad para dar a conocer mundialmente los crímenes dictatoriales (Roniger y Sznajder, 2013), el componente transnacional de la denuncia -encarnado en organismos como el Grupo de Trabajo de la ONU o la CIDH- también incidió delineando los formatos válidos para llevar adelante las denuncias.

Esta tendencia a la homogeneización de la denuncia (Crenzel, 2008) se aprecia, en el caso de los sobrevivientes, al examinar circuitos testimoniales diferentes al de la

\footnotetext{
${ }_{77}$ Memoria Abierta, Entrevista a Patrick Rice, Buenos Aires, 16 de octubre de 2001.

$78 \quad \mathrm{CIDH}, \quad$ Informe Anual $1978 . \quad$ Disponible en https://www.cidh.oas.org/annualrep/78sp/Argentina2450.htm (última consulta: 7 de mayo de 2020).

${ }^{79}$ Comisión de Derechos Humanos de la Organización de las Naciones Unidas, "Resolución №20 (XXXVI)", 29 de febrero de 1980.

80 Esta constelación de entidades era explicitada en la portada de muchos testimonios como, por ejemplo, el de Graciela Daleo y Andrés Castillo ante la CADHU, que estaba dirigido a la Organización Internacional del Trabajo (OIT), la Cruz Roja Internacional, el ACNUR, el Consejo Mundial de Iglesias, AI, Pax Cristhi, Pax romana, la Comisión Internacional de Juristas y la Organización Paz y Justicia. (Testimonio de Graciela Daleo y Andrés Castillo, Madrid, 18 de febrero de 1982).
} 


\section{"Los desaparecidos empiezan a hablar": una aproximación histórica a la producción testimonial de los sobrevivientes de la dictadura argentina desde el exilio (1976-1983)}

CADHU. En febrero de 1980, AI publicó Testimonios sobre campos secretos de detención en Argentina ${ }^{81}$. El documento, que reunía los testimonios de dos sobrevivientes de distintos CCD del Primer Cuerpo de Ejército, contaba con setenta páginas: la mitad estaban destinadas a la narración de la experiencia del cautiverio, organizada en ocho apartados temáticos ${ }^{82}$. El resto se componía de una introducción a cargo del organismo, de planos de los CCD y de tres listados donde, entre otros datos, constaban los nombres, apodos, fecha del secuestro, fuerza involucrada y lugar de cautiverio de más de trescientos secuestrados. Una estructura similar tenía el testimonio de ocho sobrevivientes del CCD "La Cacha" publicado por CLAMOR en su boletín de diciembre de 1983, compuesto de treinta y seis páginas divididas en nueve apartados ${ }^{83}$. El listado con los cautivos identificados a partir de sus rasgos biográficos fundamentales y los planos del CCD terminaban de confirmar la filiación con el nuevo modelo de relato.

El proceso de estandarización de los relatos bajo una lógica humanitaria, sin embargo, no fue total. Fieles a la impronta política del organismo, los testimonios de la serie CADHU contenían numerosas marcas de la sensibilidad revolucionaria. Una era, por ejemplo, la explicitación que algunos testimoniantes hacían de su militancia montonera ${ }^{84}$. A eso se sumaba el empleo de expresiones como "resistencia popular", "explotación" 85, "heroísmo", “quiebre político"86 o "colaboradores"87. Más llamativo resultaba, en cambio, el reconocimiento que hacía uno de los testimoniantes ante AI de su militancia en el "Peronismo Montonero"88. Del mismo modo, los sobrevivientes reunidos bajo el amparo de CLAMOR concebían su relato como "un acto de coherencia militante" 89 . Este tipo de referencias, aunque minoritarias considerando la totalidad del testimonio, evidenciaban lo inacabado del proceso de homogeneización de la denuncia bajo el formato humanitario.

\footnotetext{
${ }^{81}$ Amnistía Internacional, op. cit., 1980.

82 Estos apartados eran: "I. Los Campos; II. Proceso general de los "desaparecidos"; III. Vida dentro de los campos de concentración; IV. Los traslados y la resolución final; V. Colaboración con los servicios extranjeros; VI. Carácter mercenario de las fuerzas represivas; VII. Las compañeras embarazadas" (Idem).

${ }^{83}$ CLAMOR, op. cit., diciembre de 1983. El proyecto había sido concebido en México por una de las sobrevivientes -Alcira Ríos- y representantes de Abuelas de Plaza de Mayo, y propuesto luego a Jan Rocha. La representante del organismo brasileño hizo las gestiones para realizar el encuentro en San Pablo, al que asistieron sobrevivientes radicados en Argentina, Brasil, Italia, México y Suecia.

84 CADHU, op. cit., 12 de octubre de 1979, pp. 13 y 15. Este reconocimiento del activismo revolucionario alcanzaba su pico en el testimonio de Juan Carlos Scarpatti, quien refería su "militancia política en el Movimiento Peronista" y reconocía su pertenencia al "Partido Montonero", donde había ostentado el grado de "Oficial mayor" y de "Jefe de Propaganda del Área Federal". Todos estos detalles se explican, en parte, por el carácter confidencial del testimonio, pero aun así dan cuenta de la receptividad de la CADHU al imaginario revolucionario (CADHU, Testimonio de Juan Carlos Scarpatti, Madrid, 12 de junio de 1979, p. 1).

85 CADHU, Testimonio del ex detenido-desaparecido Juan Martin sobre campos de concentración clandestinos de la provincia de Tucumán (República Argentina), Madrid, 1982, pp. 5 y 51.

${ }^{86}$ CADHU, op. cit., 12 de octubre de 1979, pp. 6, 7 y 8.

87 CADHU, op. cit., febrero de 1982, p. 25.

${ }^{88}$ Ibidem, p. 1.

${ }^{89}$ CLAMOR, op. cit., 1983, p. 14.
} 


\section{Rodrigo González Tizón}

En paralelo a los testimonios de formato "humanitario" comenzó a circular otro tipo de relato orientado a un público más amplio que los foros internacionales de denuncia. Publicadas por sellos editoriales comerciales, estas producciones testimoniales aparecieron en distintos países del exilio, aunque su resonancia llegó hasta la Argentina, donde se reeditaron antes del retorno de la democracia. Dentro de este conjunto de relatos se podrían incluir, a pesar de sus diferencias de género y estilo, los libros L'Argentine ou le diable dans le soleil, de Carlos Gabetta, publicado en Francia en octubre de 197990; Les folles de la Place de Mai, de Jean-Pierre Bousquet, editado en ese mismo país al año siguiente ${ }^{91}$; y Preso sin nombre, celda sin número, de Jacobo Timerman, que vio la luz en Estados Unidos también en $1980^{92}$. Estos testimonios se valían de moldes más flexibles para incorporar la palabra de los sobrevivientes. El libro de Bousquet, abocado a la historia y la represión sobre las Madres de Plaza de Mayo, recurría a la entrevista periodística para traer la voz de Cecilia Vázquez, sobreviviente de El Vesubio: "Escucho a Cecilia con atención. Un rostro agradable, cabellos castaños recogidos y ojos vivaces a través de anteojos de armazón fino que caen un poco sobre su nariz"93. Un halo literario similar rodeaba al testimonio de Ana María Careaga, incluido en el capítulo "La chispa de la vida" del libro de Gabetta94. Los subtítulos que organizaban el relato seguían la misma tónica: los represores eran caracterizados como "Bestias de traje y corbata", mientras que "Mi pequeña victoria" aludía al nacimiento de la hija de la testimoniante ${ }^{95}$.

Diferente era la situación en Preso sin nombre, celda sin número, donde el autor era él mismo un sobreviviente. Jacobo Timerman había permanecido dos años y medio a merced de la Junta Militar, primero como desaparecido, luego como detenido legal y, finalmente, recluido en su hogar. El libro, que recogía el testimonio de esa experiencia, retomaba la analogía entre la represión argentina y la Shoá. Este ejercicio respondía, sobre todo, al interés personal del ex director de La Opinión de asimilar ambas masacres (Kahan, 2016). Numerosos pasajes de la obra contenían denuncias explícitas del componente antisemita de la dictadura ${ }^{96}$, a lo que se sumaban las alusiones a una supuesta "solución final" o a un eventual "Nüremberg"97. La resonancia internacional del "caso Timerman" amplificó la circulación del testimonio, reflotando en un contexto nuevo la menos novedosa interpretación de la dictadura argentina a través de la matriz del Holocausto ${ }^{98}$.

\footnotetext{
${ }^{90}$ Gabetta, Carlos. L'Argentine ou le diable dans le soleil, Paris: Atelier Marc Julian, 1979.

${ }^{91}$ Bousquet, Jean-Pierre. Les folles de la place de mai, Paris: Stock, 1980.

${ }_{92}$ Timerman, Jacobo. Preso sin nombre, celda sin número, Nueva York: Random Editores, 1981.

${ }^{93}$ Ibidem, p. 74.

${ }^{94}$ Gabetta, op. cit., p. 157.

95 Ibidem, pp. 165 y 167.

96 "A los judíos, querían borrarlos. El interrogatorio a los enemigos era un trabajo; a los judíos un placer o una maldición"; "El gobierno militar que tomó el poder en Argentina en marzo de 1976 llegó con el más completo arsenal de ideología nazi como parte importante de su estructura" (Timerman, op. cit., pp. 66 y 69).

${ }^{97}$ Ibidem, pp. 99 y 154.

${ }^{98}$ En México, el testimonio de Timerman mereció la atención de la prensa ("Protesta Argentina Ante EU: no Tenemos Campos de Concentración", Excelsior, México, 1 de julio de 1981; Espejo, Miguel. "El desgarramiento argentino II", Uno más uno, México, 3 de abril de 1982. Disponibles en el Archivo
} 


\section{“Los desaparecidos empiezan a hablar": una aproximación histórica a la producción testimonial de los sobrevivientes de la dictadura argentina desde el exilio (1976-1983)}

La contrapartida de esta mayor presencia de los sobrevivientes en el espacio público exilar fue el estallido distintas polémicas en torno a su figura y al contenido de su testimonios. La más amarga de ellas giró en torno al significado del "traslado". Su disparador fue el testimonio de París: "se nos decía que a los secuestrados se los llevaba a otras dependencias o a los campos de trabajo (...). Nos costó convencernos de que en realidad el 'traslado' conducía a la muerte", sostenían las autoras del relato ${ }^{99}$. La frase apuntaba a uno de los tópicos más sensibles del activismo antidictatorial: la pregunta por el destino de los desaparecidos, que había disparado el reclamo de los familiares por su "aparición con vida". Esta asociación entre el "traslado" y el asesinato de los secuestrados sería replicada en testimonios posteriores, disparando la polémica.

La referencia a la muerte de los cautivos, sin embargo, no resultaba del todo novedosa. Había sido deslizada en los informes de distintos organismos, como el de la CADHU de 1977, y en la producción testimonial previa, tal era el caso de los relatos difundidos por Montoneros. Para comprender el rechazo que generó esa afirmación es necesario tener en cuenta su contexto de enunciación. Un mes antes de la presentación del testimonio de París, la dictadura había promulgado las leyes Nro. 22.062 y 22.068. Las normas habilitaban a los familiares a declarar como muertos a los desaparecidos para acceder así a los beneficios previsionales. Se trataba, en realidad, de una argucia legal para evitar que el Estado diera explicaciones sobre lo ocurrido con las personas secuestradas. En estas circunstancias, un sector del activismo antidictatorial consideró que las afirmaciones de los sobrevivientes eran funcionales a la estrategia del régimen militar (Crenzel, 2008; Franco, 2008; Jensen, $2010)^{100}$.

Los organismos de familiares se pusieron a la cabeza de las críticas, que corrieron por dos vías fundamentales. Una postura moderada discutía el alcance de las declaraciones de los sobrevivientes sin impugnar los testimonios como un todo ${ }^{101}$. Este era el espíritu de la carta que diversas representaciones del COSOFAM enviaron a la CADHU el 21 de febrero de 1980, en el marco de la 36va sesión de la Comisión de Derechos Humanos de la ONU. Allí sostenían que "lo único que sabemos con certeza es que los desaparecidos han desaparecido" y, por consiguiente, "no aceptamos bajo ningún punto de vista que se publicite que la suerte corrida por los detenidos-desaparecidos trasladados desde algún campo de concentración

\footnotetext{
Nacional de la Memoria) y una reproducción parcial en el Reader's Digest ("Preso sin nombre, celda sin número", Selección del Reader's Digest, México DF, noviembre de 1982. Disponible en el Archivo Nacional de la Memoria). Documentación desclasificada de la Cancillería argentina, a su vez, da cuenta de la difusión del relato en Estados Unidos, donde Timerman dio una conferencia de prensa (Consulado Argentino en Nueva York, "Cable secreto Nro. 372", Nueva York, 24 de mayo de 1983). ${ }^{99}$ CADHU, op. cit., octubre de 1979, pp. 39-40.

100 A esto se sumaron las declaraciones del dirigente radical Ricardo Balbín, quien afirmó ante la prensa española que en la Argentina "no había desaparecidos, sino muertos" ("El Gobierno argentino considera zanjado el problema de los desaparecidos", El País, Madrid, 8 mayo de 1980).

101 COSOFAM, "Lineamientos fundamentales en las tareas de denuncia y solidaridad de CO.SO.FAM., en apoyo a la lucha de los familiares en Argentina", México, mayo de 1980.
} 


\section{Rodrigo González Tizón}

signifique automáticamente la muerte"102. Un escrito presentado por Familiares ante la ONU en octubre de 1981 evidenciaba el influjo de cierto positivismo jurídico en esta crítica: "si bien los informes de estos liberados merecen ser tenidos en cuenta en lo objetivo", planteaba el organismo, "no pueden ser tomadas en consideración consideraciones ( $\mathrm{sic}$ ) subjetivas sobre algo tan grave como la muerte de miles de personas"103.

Una postura radical esgrimía un rechazo total al contenido de los testimonios que se derivaba de una impugnación previa a los propios sobrevivientes. Este era el planteo, por ejemplo, de "un grupo de refugiados políticos argentinos en el exilio" que identificaban a algunos de los relatos publicados por la CADHU y AI como "parte de la campaña de acción psicológica lanzada por la dictadura militar fascista que trata de echar un manto de olvido sobre la cuestión de miles y miles de detenidosdesaparecidos en Argentina"104. Mediante el desprestigio de los sobrevivientes, señalados como cómplices de la estrategia dictatorial, se pretendía quitar toda verosimilitud a sus afirmaciones sobre el significado último de los "traslados"105. Acusaciones del estilo se replicaron en distintas plazas del destierro, como Francia, Suecia, España y México (Franco, 2008; Jensen, 2010).

Estos señalamientos entroncaron con la otra gran polémica que rodeó la difusión de los testimonios de los sobrevivientes durante esta etapa, centrada en la "colaboración". La falta de explicaciones de los captores para la liberación de los secuestrados, la rigidez de los esquemas militantes que planteaban la fuga o la muerte como únicas alternativas al cautiverio y la circulación de miembros de las fuerzas represivas por distintos puntos del extranjero estimularon las sospechas sobre quienes salían vivos de los CCD. Suspicacia que se potenciaba por los largos períodos de reclusión y las tareas forzadas desarrolladas durante el cautiverio. Cobró forma la idea, entre algunos actores de la comunidad exilar, de que la liberación de los sobrevivientes había sido producto de su colaboración con los represores, estigmatizándolos como "traidores" (Longoni, 2007).

La respuesta a estas acusaciones vino de los propios sobrevivientes, quienes en sus testimonios explicaron su conducta como parte de una "simulación". El recurso a esta noción, lejos de romper con el esquema de ordenamiento de las conductas de la militancia revolucionaria (Longoni, 2007; Tello, 2014), lo adaptaba a la situación del cautiverio, distinguiendo entre colaboradores "aparentes" y "reales". La

$102 \mathrm{El}$ documento estaba firmado por las representaciones de COSOFAM de Ginebra, Italia, Holanda, Madrid, París, Suecia y México (COSOFAM, "Carta a los compañeros de la CADHU", Ginebra, 21 de febrero de 1980).

${ }^{103}$ Documento de Familiares presentado ante la ONU", Ginebra, septiembre-octubre de 1981, Archivo de Familiares de Detenidos y Desaparecidos por Razones Políticas, Disponible en Memoria Abierta. ${ }^{104}$ Anónimo, "Denuncia sobre situación de detenidos-desaparecidos en la Argentina", s/l, marzo de 1980. Archivo de Familiares de Detenidos y Desaparecidos por Razones Políticas. Disponible en Memoria Abierta. Para ver una reproducción de estas acusaciones dentro de la Argentina, véase el documento "Nuestra opinión sobre denuncias y testimonios", elaborado por Familiares de Desaparecidos y Detenidos por Razones Políticas (Buenos Aires, 30 de diciembre de 1980. Archivo de Familiares de Detenidos y Desaparecidos por Razones Políticas Disponible en Memoria Abierta). ${ }^{105}$ Según Tello, por medio de esta operación "no sólo se cuestionaba la veracidad de lo dicho (...) sino que se anudaba esto a la confiabilidad de la fuente, es decir, el testigo" (2015: 100). 


\section{"Los desaparecidos empiezan a hablar": una aproximación histórica a la producción testimonial de los sobrevivientes de la dictadura argentina desde el exilio (1976-1983)}

"simulación" fue un tópico recurrente en los relatos de la CADHU, algo que no sorprende por el perfil del organismo y sus testimoniantes: "Decidí simular mi quiebre, porque vislumbré una posibilidad de sobrevivir sin dejar de lado principios políticos y morales que considero irrenunciables", sostenía una de las testimoniantes de París ${ }^{106}$. Este modo de reivindicar las conductas asumidas durante el cautiverio iba acompañado de un distanciamiento de otro conjunto de secuestrados caracterizados como "activos y efectivos colaboradores"107, "marcadores"108, "entregadores" 109 y "traidores"110. Así, la legitimación de una parte de los sobrevivientes tuvo como contraparte la estigmatización de otros, cuyo silencio se extendería por décadas ${ }^{111}$.

El debate sobre la "colaboración" fue también el terreno para dirimir divergencias políticas que iban más allá de los sobrevivientes y cuyo trasfondo era la "derrota" del proyecto revolucionario. México, donde esas disputas alcanzaron un punto álgido, fue escenario privilegiado de esta deriva. En diciembre de 1980, Héctor Schmucler publicó en la revista Controversia un artículo a propósito de los relatos que circulaban en el exilio112. Luego de reconocer que aportaban "los únicos datos directos y verosímiles que poseemos" sobre los desaparecidos, incluido su asesinato, abordaba el interrogante por los motivos de la supervivencia. La respuesta, para el autor, estaba en las voces de los propios sobrevivientes, de las cuales surgía que "una compleja red de motivaciones permitieron su sobrevida (...) algunos han dado fe de lo que pasaron. Entre otras cosas, de su colaboración con los represores"113. Lejos de constituir una "traición", esa conducta evidenciaba la derrota del proyecto político revolucionario. Una "derrota que es previa", sentenciaba Schmucler, poniendo el debate sobre la "colaboración" al servicio de su pugna personal con Montoneros ${ }^{114}$.

\footnotetext{
106 CADHU, op. cit., 12 de octubre de 1979, p. 10. El testimonio de Graciela Daleo es elocuente al respecto: "formé parte del grupo de secuestrados que adoptamos una conducta de simulación de colaboración con los planes de la Armada, aparentando ser receptiva al 'proceso de recuperación' que intentaron los marinos ensayar conmigo. Esto me permitió acceder a la libertad, habiendo mantenido dentro del campo de concentración una conducta acorde con los ideales que he defendido durante toda mi vida de militante" (CADHU, op. cit., 18 de febrero de 1982, p. 8).

107 CADHU, Testimonio de Graciela Daleo y Andrés Castillo, Madrid, 18 de febrero de 1982, p. 24.

108 Ibidem.

${ }^{109}$ CADHU, Testimonio de Lisandro Raúl Cubas y Rosario Quiroga, Madrid, 1982, p. 23.

110 MPM, op cit., septiembre de 1978, p. 5.

111 Paradójicamente, esta construcción de sentidos fue también estimulada por algunas de las entidades que difundieron la palabra de los sobrevivientes, como la CADHU. En su informe sobre el CCD "La Perla", publicado en Madrid en 1980, el organismo incluyó un apartado titulado "La colaboración organizada". Allí señalaba a algunos secuestrados en particular como partícipes activos de la represión. Estas acusaciones se reforzaron en los listados de secuestrados del documento, donde esos cautivos eran etiquetados como "colaboradores" o "civiles adscriptos" (CADHU, Informe del campo de concentración y exterminio 'La Perla',1980). Para observar los efectos que tuvieron estas acusaciones en la palabra testimonial de los sobrevivientes, ver Feld y Messina (2014).

112 Schmucler, H., op. cit., diciembre de 1980.

113 Ibidem, p. 4.

${ }^{114}$ Ibidem. Esta animosidad se explicaba en buena medida por la desaparición del hijo de Schmucler, militante de esa organización, asesinado por la dictadura el 29 de enero de 1977 en la ciudad de La
} 


\section{Rodrigo González Tizón}

La operación no pasó desapercibida a los sobrevivientes, quienes contestaron desde las páginas de Controversia en agosto de 1981115. Escrito en el exilio italiano, "Tres sobrevivientes responden" -cuyos autores habían permanecido cautivos en el CCD "La Perla", en Córdoba- impugnaba las reflexiones de Schmucler con argumentos forjados en la sensibilidad revolucionaria: rechazaban su "propósito de mostrar a todas las víctimas de los campos de concentración como seres alienados (...), derrotados absolutamente en lo político, en lo ideológico, en lo humano [y] "dispuestos al servicio de los militares y sus intereses"116. Si bien coincidían en que "hubo derrota", sostenían que "allí, bajo el peso de ella, hubo resistencia". Esta se materializaba en la "actitud de lucha" de los cautivos, que marcaba "la continuación de su conducta anterior". El saldo era "resistencias heroicas y derrotas parciales", que sólo en una "ínfima minoría" se habían traducido en colaboración efectiva. La respuesta incluía una reivindicación del activismo en clave humanitaria: “¿Acaso no es la denuncia un enfrentamiento al enemigo? ${ }^{117}$. El interrogante dejaba entrever la valoración positiva que los sobrevivientes hacían de los repertorios políticos gestados en el exilio, sin por eso abandonar del todo sus convicciones preexistentes. La incorporanción de estos modos de acción novedosos iba acompañada de nuevos límites de lo decible. El último apartado del artículo acusaba recibo de la polémica del "traslado". "Respecto de este tema tan controvertido", afirmaban los autores del escrito, "nosotros sobrevivientes (...) queremos (...) no mezclar nuestras conclusiones personales (...) con la descripción lo más fiel posible de los hechos"118. Las palabras recordaban la diferenciación entre componentes "objetivos" y "subjetivos" del testimonio que postulaba el documento de Familiares. En el nuevo escenario de denuncia, la necesidad de construir acuerdos políticos parecía marcar la frontera de lo que podían o no decir los sobrevivientes.

A pesar de estos intentos de acercamiento, la cuestión resurgiría numerosas veces como objeto de debate en el exilio, evidenciando su carácter polémico. Así ocurrió, por ejemplo, en una fecha tardía como octubre de 1983 cuando, ante la posibilidad de que se realizara una publicación en base a relatos de sobrevivientes, Familiares envió una comunicación a COSOFAM México donde afirmaba que "una vez más los testimonios surgen como tema de polémica para nosotros"119. Luego de apelar a los viejos argumentos impugnatorios de la palabra de los sobrevivientes, el organismo

Plata. El intelectual responsabilizada a la Conducción montonera por exponer a sus militantes al no ordenarles la salida del país inmediatamente después de consumado el golpe de Estado.

115 El texto de Schmucler motivó una dura respuesta de Mempo Giardinelli, también exiliado en México, publicada en las páginas de la revista Cuadernos de Marcha bajo el título "Los sobrevivientes de los testimonios" (Cuardernos de Marcha, op. cit.).

116 Callizo, L., Meschiatti, T. y Di Monte, P., op. cit., p. 29.

117 Ibidem, p. 30.

118 Ibidem, p. 31.

119 Familiares de Detenidos y Desaparecidos por Razones Políticas, Correspondencia con el COSOFAM, Buenos Aires-México, 6 de octubre de 1983. Disponible en Memoria Abierta. 


\section{"Los desaparecidos empiezan a hablar": una aproximación histórica a la producción testimonial de los sobrevivientes de la dictadura argentina desde el exilio (1976-1983)}

cerraba su razonamiento de manera taxativa: "estamos en la etapa de luchar por los desaparecidos que ESTÁN VIVOS”120.

\section{Reflexiones finales}

El 19 de octubre de 1983, la revista Siete días publicó un artículo titulado "Los desaparecidos empiezan a hablar"121. Allí se reproducía el testimonio del sobreviviente de la ESMA Raúl Cubas ante American Watch y AI en Washington. La introducción, a cargo del periodista Mario Diament, ofrecía una instantánea del clima político de la transición. Luego de presentar a Cubas como "un militante de la tendencia revolucionaria del peronismo", se condenaba la "descarnada crueldad" con la que ese sector había utilizado la violencia. Sin embargo, esa era sólo "una cara de la tragedia argentina"; la otra "implicó la utilización de todos los recursos a disposición del Estado y de las Fuerzas Armadas para combatir un delito con otro delito". El tono epocal se encarnaba, también, en el tratamiento de la palabra de los sobrevivientes, que se presentaba como una novedad absoluta, tal como lo sugería el encabezado.

La irrupción pública de los relatos del cautiverio clandestino durante la transición generó un oscurecimiento de su producción testimonial previa. Este trabajo se abocó a un análisis de ese acervo inicial de relatos, cuyo epicentro fue el exilio, identificando distintas etapas en su evolución histórica. Durante el primer año de dictadura, los testimonios, escasos y dispersos, aportaron un saber temprano sobre el dispositivo represivo, cuya finalidad era alertar a la comunidad internacional de la situacion en Argentina y, así, salvar a los desaparecidos. El primer aniversario del golpe de Estado marcó el inicio de otra fase en la que el crecimiento cuantitativo de los relatos coincidió con la conformación de los principales circuitos testimoniales, estructurados en torno a entidades políticamente heterogéneas. Algunas estaban en las antípodas ideológicas, como AI y Montoneros, lo que sugiere un consenso respecto a la eficacia de la difusión de la palabra de los sobrevivientes. La coyuntura abierta con la visita de la CIDH dio paso a una tercera etapa en la que los testimonios, bajo nuevos formatos, alcanzaron su máxima circulación pública. El contrapunto de esta "era del testigo" fueron los cruces generados por el contenido de los relatos.

La reconstrucción realizada habilitó también una reflexión sobre esas tensiones. Tanto la bibliografía especializada como los escritos testimoniales refieren al silenciamiento público de los sobrevivientes provocado por las sospechas de

\footnotetext{
120 Previo a eso, El Día había publicado un artículo titulado "Existen desaparecidos vivos" donde se daba cuenta de un documento del COSOFAM en el que se afirmaba la presencia de personas con vida en los CCD. La fuente de esa información era el relato de una sobreviviente cuya identidad se mantenía en reserva (México, 16 de febrero de 1983).

121 Diament, Raúl. "Los desaparecidos empiezan a hablar", Siete días, 19 de octubre de 1983. Disponible en el Archivo Nacional de la Memoria.
} 


\section{Rodrigo González Tizón}

"traición" que pesaron sobre sus espaldas. Esta interpretación, que cristalizó como un sentido común en torno a la sobrevivencia, tomó como base acusaciones que efectivamente existieron y se potenciaron en coyunturas puntuales como la polémica del "traslado". No obstante, la abundancia y la riqueza de la producción testimonial analizada permite afirmar que ese silenciamiento, al menos durante la dictadura, fue relativo: junto a esas posturas impugnatorias de la palabra de los sobrevivientes, circunscriptas a individuos y actores específicos, existieron otras que reivindicaron su empleo como herramienta de denuncia, dándoles amplia difusión en el exilio.

El análisis de la producción testimonial de los sobrevivientes permitió, además, explorar fenómenos generales del activismo exilar. Uno fue la relación que existió entre las lógicas políticas revolucionaria y humanitaria en el terreno de la denuncia. Si bien se observó un paulatino predominio de la segunda conforme avanzaba la dictadura, al menos en lo concerniente a los testimonios de los sobrevivientes no es posible hablar de una evolución lineal o de una homogeneización política bajo un único paradigma: a la vez que se identificaron rasgos de la denuncia humanitaria en los comienzos de la dictadura, tales como el énfasis en los datos fácticos y en la descripción de las torturas, también se registraron trazas de la sensibilidad revolucionaria en los años finales del régimen militar, cuya máxima expresión la constituyen las menciones a la militancia armada en los testimonios de la CADHU o -más sorprendente aún- de AI. Estas evidencias advierten contra interpretaciones tendientes a una disociación tajante de ambos universos políticos o una sustitución total de uno por otro, haciendo hincapié en la heterogeneidad que asumió el proceso histórico.

Otro aspecto que surge es la naturaleza transnacional del activismo en el exilio. En el caso de los testimonios de los sobrevivientes, esto se evidenció en su circulación más allá de las fronteras de los estados receptores y de los circuitos testimoniales específicos. Esto ocurrió, por ejemplo, con el relato de Patrick Rice, que fue difundido en Francia a través del CAIS, luego en Inglaterra y España por medio de AI y, por último, personalmente en el Congreso de Estados Unidos. Este tipo de situaciones, que no fueron aisladas, sugieren que el elemento definitorio del mapa de la producción y la circulación de los testimonios no fue la fisonomía política de los países de acogida -que, no obstante, tuvo su incidencia-, sino una "estructura de posibilidades" de la denuncia modelada por las redes transnacionales de organismos de derechos humanos y los foros humanitarios internacionales.

El itinerario recorrido permitió bucear, también, en el proceso de construcción de categorías de víctimas de la represión dictatorial. De la misma manera que con los desaparecidos, la naturaleza atroz e inédita del crimen evidenció la ausencia de una terminología adecuada para denominar a quienes salían con vida de los CCD en los comienzos de la dictadura. El empleo inicial de nociones relativas a la prisión política fue un indicio de esa dificultad. Pasaron años hasta que, en un contexto marcado por las afirmaciones sobre el asesinato de los desaparecidos, hizo irrupción pública el término "sobrevivientes". Su propagación entre los actores del exilio, 


\section{“Los desaparecidos empiezan a hablar": una aproximación histórica a la producción testimonial de los sobrevivientes de la dictadura argentina desde el exilio (1976-1983)}

síntoma de la buena recepción que tuvo la noción, no impidió su convivencia con otras nociones como las de "ex detenidos", "liberados" "reaparecidos" o "desaparecidos". En última instancia, la situación evidenciaba las dificultades que existían todavía para consensuar una categoría que diera cuenta de esa porción de las víctimas de la represión.

Durante la transición democrática, el "show del horror", la CONADEP y el Juicio a las Juntas catapultaron los relatos del cautiverio clandestino al primer plano de la escena pública local. En este marco, que coincidió con la cristalización de una primera memoria social de la dictadura, los sobrevivientes se consagraron en su rol de testigos de los crímenes de la represión estatal. Este trabajo demostró que esa producción testimonial de la temprana democracia tuvo un antecedente fundamental en los relatos difundidos en el exilio. Mediante su estudio se pretendió aportar a la comprensión de un capítulo aún poco explorado del activismo antidictatorial que cobró forma más allá de las fronteras argentinas.

\section{Bibliografía}

Acha, 0. (2010). La nación futura. Rodolfo Puiggrós en las encrucijadas argentinas del siglo XX, Buenos Aires: EUDEBA.

Alonso, L. (2013). "La definición de las ofensas en el movimiento por los derechos humanos en Argentina y la calificación de 'Genocidio'”, en Contenciosa, año I, nํ⒈

Ayala, M. (2019). “'Reaparecer en el exilio': experiencias de militantes argentinos sobrevivientes de desaparición forzada en Venezuela (1979-1984)", en Tempo, vol. 25 , no. 2 .

Calveiro, P. (1998). Poder y desaparición. Los campos de concentración en Argentina, Buenos Aires: Colihue.

Calveiro, Pilar (2006). "Testimonio y memoria en el relato histórico", en Acta Poética, 27, otoño.

Canelo, P. (2008). El proceso en su laberinto. La interna militar de interna a Bignone, Buenos Aires: Prometeo.

Carnovale, V. (2011). Los combatientes. Historia del PRT-ERP, Buenos Aires, Siglo XXI. 


\section{Rodrigo González Tizón}

Catoggio, S. (2016). "Integración latinoamericana contra la coordinación represiva y por una política regional de los derechos humanos. El caso CLAMOR”, en Funes, P. (dir.). Revolución dictadura y democracia. Lógicas militantes y militares en la historia argentina en el contexto latinoamericano, Buenos Aires: Imago Mundi

Confino, H. (en prensa). "Las redes montoneras en el exilio. Revolución, solidaridad y derechos humanos (1974-1980)".

Copello, D. (2019). "Faire la révolution par les droits de l'homme. Un phénomène d'imbrication militante dans l'Argentine des années 1970 et 1980", en Revue Française de Science Politique, Vol. 69, No. 4.

Crenzel, E. (2008). La historia política del Nunca más. La memoria de las desapariciones en la Argentina. BuenosAires: Siglo XXI.

Feld, C. y Franco, F. (2019). "Las tramas de la destrucción: prácticas, vínculos e interacciones en el cautiverio clandestino de la ESMA", Quinto Sol, 23:3.

Feld, C. y Messina, L. (2014), "En torno a la palabra testimonial de los sobrevivientes: testigos legitimados y denegados de los centros clandestinos de detenciónen Argentina", en Tramas, Nro. 41.

Fernández Meijide, G. (2009). La historia íntima de los derechos humanos en la Argentina (a Pablo), Buenos Aires: Sudamericana.

Franco, M. (2008). El exilio. Argentinos en Francia durante la dictadura, Buenos Aires: Siglo XXI.

Franco, M. (2012). Un enemigo para la nación. Orden interno, violencia y “subversión", 1973-1976, Buenos Aires: Fondo de Cultura Económica.

Franco, M. (2019). El final del silencio: dictadura, sociedad y derechos humanos en la transición (1979-1983), Buenos Aires: Fondo de Cultura Económica.

González Tizón, R (2016). "'Cada voz que se alce puede salvar una vida en Argentina'. La producción testimonial de los sobrevivientes de los Centros Clandestinos de Detención en el marco de la Comisión Argentina por los Derechos Humanos", en Papeles de Trabajo, 10 (17).

González Tizón, R (2018). Militancia humanitaria y testimonio. Los sobrevivientes de "El Vesubio" y la denuncia de los crímenes de la última dictadura (1978-2016), Tesis de Doctorado en Historia, IDAES-UNSAM.

Guest, I. (1997). Behind the disappearances. Argentina's dirty war against human rights and the United Nations, Estados Unidos: University of Pennsylvania Press. 


\section{“Los desaparecidos empiezan a hablar": una aproximación histórica a la producción testimonial de los sobrevivientes de la dictadura argentina desde el exilio (1976-1983)}

Gutman, D. (2015). Noviembre de 1976. Una misión en busca de la verdad, Buenos Aires: Capital Intelectual.

Jensen, S. (2010). Los exiliados. La lucha por los derechos humanos durante la dictadura, Buenos Aires, Sudamericana.

Jensen, S. (2014). "Las fuentes de oposición exiliar y el estudio de las actitudes sociales durante el último gobierno militar en Argentina (1976-1979), ponencia presentada en II Jornadas de trabajo sobre Exilios Políticos del Cono Sur en el siglo XX. Agendas, problemas y perspectivas conceptuales, FHyCE, Universidad de la República, Montevideo.

Jensen, S. (2019). “Los exiliados argentinos y los sentidos del Núremberg: de recurso pedagógico a estrategia de persecución penal de los crímenes de la última dictadura militar (1976-1983)", en Folia Histórica del Nordeste, Nro. 34.

Kahan, E (2016). "Esto no es un Holocausto. El testimonio de Jacobo Ti m merman y la represión a l os judío s durante la última dictadura militar". En Águila, Gabriela et al, Represión estatal y violencia paraestatal en la historia reciente argentina. Nuevos abordajes a 40 años del golpe de Estado, Buenos Aires: FaHCE UNLP.

Longoni, A. (2007). Traiciones. La figura del traidor en los relatos acerca de los sobrevivientes de la represión, Buenos Aires: Norma.

Pollack, M. (2006). Memoria, olvido, silencio. La producción social de identidades frente a situaciones límite, La Plata: Ediciones al Margen.

Rama, C. (2019). "La reaparición de Alicia Partnoy: Historia del exilio de una sobreviviente de los espacios de detención clandestina de la última dictadura en Argentina (1976-1983)", en Avances del CESOR, Rosario.

Rocha, J. (2018). A solidariedade não tem fronteiras: a história do grupo Clamor com os refugiados sul-americanos. São Paulo: Outras Expressões.

Sznajder, M. y Roniger, L. (2013) La política del destierro y el exilio en América Latina, México: Fondo de Cultura Económica.

Rot, G. (2015). Itinerarios revolucionarios: Eduardo L. Duhalde - Haroldo Logiurato. De la resistencia peronista al Partido Revolucionario de los Obreros Argentinos, Buenos Aires: El Topo Blindado.

Serra Padrós, (2014). “CLAMOR: a solidaridade contra o terrorismo de Estado e a Operacão Condor, Projeto História, São Paulo. 
Tello, M. (2014). “Una vara con qué medirnos: una lectura antropológica sobre los sentidos de la transgresión y la 'traición' en las memorias sobre la militancia en 'los 70"', en Contenciosa, año II, número 3, segundo semestre de 2014.

Tello, M. (2015), "Yo acuso: un análisis antropológico sobre lo jurídicoen los primeros testimonios acerca de La Perla", en Clepsidra. Revista interdisciplinaria de estudios sobre memoria, noㄴ, pp.90-115, octubre de 2015.

Tolentino, M. (en prensa), "O Clamor dos campos de concentração": a produção de saberes e discursos sobre os sobreviventes dos centros clandestinos de detenção argentinos no arquivo do CLAMOR (1978-1984).

Wieviorka, A. (1998). L'ere du témoin, Paris: Hachette, 1998.

Yankelevich, P. (2010), Ráfagas de un exilio. Argentinos en México: 1974-1983, Buenos Aires: Fondo de Cultura Económica.

Recibido: 20/05/2020

Evaluado: $29 / 06 / 2020$

Versión Final: 29/07/2020 